\title{
UNA APROXIMACIÓN A LA DIPLOMÁTICA EPISCOPAL EN LA EDAD MODERNA, SIGLOS XVI-XVIII*
}

\author{
Francisco Luis Rico Callado \\ Grupo de investigación ARDOPA, Universidad de Extremadura \\ franciscorico@unex.es
}

\begin{abstract}
RESUMEN: Los estudios sobre diplomática episcopal en la Edad Moderna son muy escasos. A partir de fondos procedentes de diferentes diócesis, este trabajo pretende aproximarse a dicha cuestión a través del estudio de la conscriptio y de una descripción de algunos de los tipos documentales más significativos. Asimismo, se atiende a operaciones como el registro o la tasación. Tras destacar algunas diferencias puntuales, se descubren los rasgos comunes de la documentación episcopal de las diferentes circunscripciones, tanto desde un punto de vista tipológico como en lo que respecta a la generación de los documentos.
\end{abstract}

Palabras clave: documento, conscriptio, tipo documental, obispo, Edad Moderna, Diplomática.

\section{AN APPROACH TO THE EPISCOPAL DOCUMENTATION IN THE EARLY MODERN AGE, XVITH-XVIIITH CENTURIES}

ABSTRACT: Studies about episcopal Diplomatic in the Early Modern Age in Spain are scarce. Using documentary sources from different dioceses, the author proposes an approach to this question throughout the study of the conscriptio and the description of some of the most significant documentary types. Operations such as registration or taxation are studied too. After remarking some differences, the paper insists on the common features of the episcopal documentation of the different circumscriptions, studied not only from the typological point of view but in the uses, which structured the generation of documents. 
Keywords: Document, conscriptio, documentary type, bishop, Early Modern Age, Diplomatic.

Recibido: 2 de febrero de 2021 Aceptado: 28 de abril del 2021

Los procedimientos gubernativos eclesiásticos de la Edad Moderna entrañaron la verificación de unos trámites que tuvieron un reflejo escrito, conformando expedientes de mayor o menor amplitud. En lo que respecta a dichas actuaciones, se puede afirmar que las curias diocesanas se inspiraron, en buena medida, en las disposiciones adoptadas en los procedimientos judiciales, una circunstancia que se evidencia también en los tipos documentales que se usaron, que en algunos casos fueron los mismos.

Frente a la Diplomática centrada en Edad Media, en el ámbito de la documentación de la Edad Moderna no se puede considerar, sin más, el documento final que contiene la disposición de una determinada institución. Por el contrario, este debe relacionarse con el expediente que lo originó. Ha de ser explicado y entendido desde un contexto histórico e institucional, a la vez que documental, incardinándolo en la actividad de la institución que lo generó.

De forma genérica, podemos distinguir varias fases en los procedimientos. En primer lugar tenemos la iniciación. Esta podía ser de oficio o a petición de parte. En este último se verificó mediante una petición o súplica.

En cuanto a la tramitación, hemos de destacar que la administración diocesana primó una labor inquisitiva, de modo que las peticiones de los interesados debían corresponderse con unos hechos acreditados. Esto se verificó, usualmente, de dos formas: bien mediante informaciones, bien mediante informes remitidos por los sacerdotes o vicarios locales. Las primeras se hicieron efectivas mediante interrogatorios de testigos que se recogieron en documentos cuya estructura es la misma que la de las probanzas judiciales. Los segundos se verificaron mediante oficios. Estos fueron muy similares a los empleados en las distintas instituciones de la Monarquía, de modo que se inspiraron, en cierta medida, en los formulismos propios de la correspondencia'.

1. *Esta investigación ha sido posible gracias a la financiación concedida al grupo de investigación "Archivística y documentación del patrimonio artístico" (ARDOPA) por el Gobierno de Extremadura, cofinanciada con fondos FEDER: "Programa operativo FEDER de Extremadura, 2014-2020. Consejería de Economía e Infraestructuras. Junta de Extremadura. Ayuda para la realización de actividades de investigación y desarrollo tecnológico de divulgación y de transferencia de conocimiento por los grupos de investigación de Extremadura".

Debo de agradecer a la directora de los Archivos eclesiásticos de Mérida-Badajoz, $\mathrm{D}^{\mathrm{a}}$ María Guadalupe Pérez Ortiz, tanto su asesoramiento como su atención durante el desarrollo del trabajo de investigación en que se basa esta contribución. 
Otro elemento importante de los trámites tuvo que ver con la salvaguarda de los derechos de terceros. En ocasiones, los afectados o interesados fueron convocados mediante edictos u otros anuncios públicos. Estos permitieron dar a conocer a los posibles candidatos las vacantes de los beneficios eclesiásticos, en aquellos casos en que estos se proveyeron mediante un concurso.

Los expedientes se resolvieron, en general, mediante un decreto. Desde un punto de vista procedimental se puede distinguir este último de los que sirvieron para impulsar la tramitación, Dicho documento fue empleado, con frecuencia, para comunicar la decisión. Asimismo, como se observa en las circunscripciones episcopales estudiadas en este trabajo, las resoluciones de los oficiales o del propio obispo, particularmente las de "trámite", quedaron reflejadas en certificaciones expedidas por los notarios de la audiencia episcopal o, en su caso, por el titular de la secretaría del prelado².

Estos dos órganos constituyeron la curia diocesana y entre ellos se dividió el trabajo administrativo. Si bien la secretaría se ligó directamente a la actividad del prelado, este también contó para escriturar los negocios con el auxilio de los notarios de la audiencia y, a su vez, de los de las visitas, cuando estuvo al frente de ellas. Una de las cuestiones que ha atraído la atención de los diplomatistas es la estructura de la curia y, particularmente, de los oficiales involucrados en la confección de los documentos. A este respecto, junto con las aportaciones centradas en Valencia, cabe citar las relacionadas con otros obispados, como Zaragoza, Santiago de Compostela, Cuenca o Murcia ${ }^{3}$.

Pedro Luis LORENZO CADARSO: "La correspondencia administrativa en el Estado absoluto castellano (siglos XVI-XVII)", Tiempos Modernos, 2-6 (2001). Para el ámbito diocesano: Una aproximación a estas cuestiones, a través del estudio de la correspondencia administrativa en: Francisco Luis RICO CALLADO: "La correspondencia gubernativa en los obispados españoles en la Edad Moderna (siglos XVII-XVIII)", Documenta \& instrumenta, 19 (2021), en prensa.

2. Francisco Luis RICO CALLADO: "La correspondencia gubernativa...".

3. Entre otros, podemos citar: María Milagros CÁRCEL ORTí y Vicente PONS ALÓs: "Curia, casa y corte valentina del cardenal Rodrigo de Borja, obispo de Valencia (1458-1492)", en María del Val GONZÁLEZ DE LA PEÑA: Estudios en memoria del profesor Dr. Carlos Sáez: homenaje, Alcalá de Henares, Universidad de Alcalá de Henares, 2007, pp. 415-438. María Milagros CÁRCEL ORTÍ: "Documentación judicial de la administración episcopal valentina: procesos del Oficialato de Valencia y Xàtiva (siglos XIV-XVI)", en Giovanna NICOLAJ: La diplomática dei documenti giudiziari (dai placiti agli acta-secc. XII-XV): Bologna 12-15 settembre 2001, Città del Vaticano, Scuola Vaticana di Paleografia, Diplomatica e Archivistica, 2004, pp. 137-205. María Milagros CÁRCEL ORTí: “Casa, corte y cancillería del obispo de Valencia Hug de Llupià (1398-1427)", Anuario de estudios medievales, 28 (1998), pp. 635-660. Iluminado SANZ SANCHO: "Notas sobre la casa de los obispos de Córdoba en la Edad Media", Espacio, Tiempo y Forma, 18 (2005), pp. 245-264. Mercedes VÁZQUEZ BERTOMEU: “La audiencia arzobispal compostelana", Cuadernos de estudios gallegos, 110 (1998), pp. 9-29. María Pilar RÁBADE OBRADÓ: “Una aproximación a la cancillería episcopal de Fray Lope de Barrientos, obispo de Cuenca", Espacio, Tiempo y Forma, 7 (1994), pp. 191-204. Francisco Reyes MARSILLA DE PASCUAL: "En torno a la diplomática episcopal y capitular castellana bajomedieval: 
Nos centramos en los instrumentos que sirvieron para comunicar las decisiones y su conscriptio. Esta última es una cuestión difícil de reconstruir, dado el estado de los fondos que utilizamos como base para este trabajo, una situación que se puede extender a otras diócesis, como Zamora o Salamanca. A continuación, analizamos las tipologías documentales, destacando, en primer lugar, sus rasgos generales para detallar, a continuación, los formularios de cada uno de los tipos.

Salvo contadas excepciones, carecemos de trabajos importantes sobre diplomática episcopal en la Edad Moderna ${ }^{4}$. Las aproximaciones a dicha cuestión se han centrado, por tanto, en la documentación medieval. En ellas se han propuesto clasificaciones basadas en el asunto jurídico, una circunstancia que se explica por la dificultad de establecer una clasificación estrictamente diplomática debido a la naturaleza de las fuentes empleadas en dichas investigaciones, esto es, los registros de la cancillería episcopal, donde se omitieron un buen

una aproximación", Miscelánea medieval murciana, 19-20 (1996), pp. 153-172. Para la Edad Moderna no hubo cambios en la configuración básica de las curias diocesanas podemos: Rafael MARÍN LÓPEZ: "Diplomática eclesiástica granadina". José Antonio PINEDA ALFONSO: EI gobierno arzobispal de Sevilla en la Edad Moderna (siglos XVI-XVII), tesis de doctorado, Sevilla, Universidad de Sevilla, 2015. Francisco Luis RICO CALLADO: “El gobierno de las diócesis y su configuración institucional: las curias diocesanas y su estructura en la Corona de Castilla en la Edad Moderna (ss. XVI-XVIII)", Ius Canonicum, 60-120 (2020), pp. 1-45.

Desde el punto de vista de la Archivística son interesantes: Pedro RUBIO MERINO: Archivística eclesiástica: nociones básicas, Sevilla, Guadalquivir Ediciones, 1999. Luis Miguel de la CRUZ HERRANZ: "Documentación eclesiástica no pontificia", en Juan Carlos GALENDE DÍAZ (dir.): La diplomática y sus fuentes documentales, Madrid, Asociación de Amigos del Archivo Histórico-Nacional y Universidad Complutense, 2020, pp. 127-186.

4. Particularmente: Rafael MARíN LÓPEZ: "Diplomática eclesiástica granadina". Esta aportación omite algunos tipos documentales significativos, como los relacionados con las órdenes y se basa, en buena medida, en lo establecido en las constituciones sinodales. Como ocurre en otros archivos diocesanos, como en el de Salamanca, la documentación del siglo $\mathrm{XVI}$ es escasa, circunstancia que, unida a la falta de registros, dificulta la tarea del diplomatista que aborda la documentación de dicha centuria. Respecto a la documentación episcopal medieval, además de los que citaremos a continuación, véanse: María Milagros CÁRCEL ORTí: "El documento episcopal. Estado actual de sus estudios", Boletín de la Sociedad Castellonense de Cultura, LVIII (1982), pp. 471-511. María Milagros CÁRCEL ORTí: "Diplomática episcopal de Valencia (1240-1300)", en Christoph HAIDACHER, y Charles KÖFLER (eds.): Die Diplomatik der Bischofsurkunde vor 1250. La Diplomatique épiscopale avant 1250, Innsbruck, Tiroler Landesarchiv, 1995, pp. 393-401; Pilar PUEYO COLOMINA: "Diplomática episcopal Cesaraugustuana anterior a 1318", en ídem, pp. 411-427. Pilar OSTOS SALCEDO: "Documentos y cancillería episcopal de Burgos, anterior a 1300", ídem, pp. 429-451. María Luisa PARDO RODRÍGUEZ: "Documentos y cancillerías episcopales de la Andalucía bética en el siglo XIII. Las sedes de Baeza-Jaén, Córdoba y Sevilla", en ídem, pp. 453-466. María Josefa SANZ FUENTES: "Documento y cancillería episcopal en Oviedo anterior a 1300", en ídem, pp. 467-482. Ángel RIESCO TERRERO: "Consideraciones en torno a la Diplomática episcopal antigua y medieval (s. V-XIII)", en Homenaje al profesor Juan Torres Fontes, vol. II, Murcia, Universidad de Murcia, 1987, pp. 1387-1399. 
número de las cláusulas de los documentos mediante etcéteras. De cualquier forma, se establece una diferenciación entre dos categorías: permisos y mandatos. Entre los primeros estarían las licencias, así como los referidos a las órdenes. En cuanto a los segundos, englobarían los mandamientos propiamente dichos o las comisiones, entre otros ${ }^{5}$. Esto no afectó, como veremos, al tenor documental que siguió siendo, en general, el de littera, propia del periodo bajomedieval.

En este trabajo utilizamos, esencialmente, fondos procedentes de dos diócesis: los de la vicaría santiaguista de León y, más concretamente, los de su provisorato, y los de Badajoz. En este último caso se han rastreado no solamente los expedientes del juez episcopal, sino que también se han analizado los escasos instrumentos emanados por la secretaría episcopal correspondientes a los siglos XVI-XVIII.

\section{La conscriptio}

En los expedientes quedaron testimonios breves, en forma de notas, de uso interno, de las decisiones adoptadas por las autoridades episcopales. Tanto en el caso de la secretaría episcopal como en el del provisorato, se asentaron en los vueltos de las peticiones u oficios, durante el siglo XVI y principios del siglo XVII. Asimismo, particularmente en esta última centuria, las encontramos en la parte superior de los folios y en el margen. En ocasiones, incluyeron una rúbrica que correspondió, en lo que respecta a los asuntos tramitados por el obispo, a su secretario y, en el del provisorato, a los propios jueces y, otras veces, a los notarios encargados del expediente. Todos ellos las asentaron, por regla general, de su propia mano. Las correspondientes a las sentencias fueron escrituradas, en ocasiones, por los provisores.

En las oficinas reales, tras ello se verificaron las operaciones necesarias para "...formar y componer, in extenso, con todas sus solemnidades, un documento como medio en el que se materializa y transmite una resolución..." ${ }^{6}$. En los obispados nos encontramos con que, en primera instancia, se hizo lo oportuno con los decretos, si bien esto no se verificó en un buen número de ellos, particularmente los relacionados con la tramitación de los asuntos, tanto en el siglo XVI como a comienzos del XVII.

5. Estas últimas tuvieron la misma estructura que las empleadas en los trámites judiciales. Respecto a la distinción entre los dos grupos de documentos que referimos, véase: Pilar PUEYO COLOMINA: "El registro de actos comunes del arzobispo de Zaragoza, Pedro de La Jugie (1346-1347)", Aragón en la Edad Media, 10-11 (1993), pp. 269-312; Pilar PUEYO COLOMINA: "Aproximación a una tipología documental de los registros de actos comunes de la diócesis de Zaragoza durante el arzobispado de Pedro de La Jugie (1345-1347)", Aragón en la Edad Media, 8 (1989), pp. 523-536.

6. Margarita GÓMEZ GÓMEZ: Forma y Expedición del Documento en la Secretaría de Estado y del Despacho Universal de Indias, Sevilla, Universidad de Sevilla, 1993, p. 163. 
Como hemos señalado, hay que considerar que estos últimos fueron elegidos para comunicar las decisiones, una circunstancia de la que se dejó constancia en ellos: "que por este su auto, que servía de despacho en forma, así lo proveyó, mandó y firmó en santa visita"7. Esto ocurrió también en otras diócesis del Reino de Castilla. Así, por ejemplo, en una revocación de la concordia establecida con el arcediano de Ledesma para proveer las rentas eclesiásticas que vacaron en dicho arciprestazgo, adoptada por el obispo de Salamanca don Fernando de Manrique, se notificó el decreto mediante un notario y, además, se ordenó que para que quedase constancia de ello se pusiese "... esta revocación en la dicha concordia" ${ }^{\prime \prime}$. Otras veces se dispuso que se transmitiese a los interesados una copia, como ocurrió en el caso de la aprobación del nombramiento de San Blas como patrono que el concejo de la villa de Castellanos, en la diócesis de Salamanca, acordado el cuatro de diciembre de 1643:

para que llegue a nota de todos, se publique un día de fiesta en la iglesia del dicho lugar y el vicario o cura lo publique, por de guardar de precepto, al pueblo cuando tienen obligación de avisar los días de fiesta de la semana y para ello se les dé un tanto de este auto signado 9 .

Con frecuencia, los decretos se escrituraron en las peticiones de los interesados, a quienes se devolvieron para que las conservasen y ejerciesen su derecho, como se observa en los instrumentos conservados tanto en archivos familiares como en los fondos diocesanos ${ }^{10}$.

En otras ocasiones, en cambio, las resoluciones se transmitieron mediante otros documentos. En principio, no podemos reconstruir con precisión la elaboración de todos ellos, a falta de datos. De acuerdo con los esquemas manejados por los diplomatistas, las operaciones correspondientes consistieron en la elaboración de la minuta, su puesta el limpio y la validación del instrumento. En cuanto a la confección de la primera, había una serie de pasos, entre los cuales, el "planteamiento" implicó la elección de la forma y tenor

7. Archivos eclesiásticos de la diócesis de Mérida-Badajoz (AEDMB). Fondos órdenes militares. Orden de Santiago exp. 32701. Otros ejemplos de ello: "que por este su auto, que sirva de despacho en forma, así lo proveyó, mandó y firmó" (AEDMB. Fondos órdenes militares. Orden de Santiago, leg. 424, exp. 17446). Esto ocurrió también con los relativos a la realización de trámites, por ejemplo, el encargo de la realización de diligencias: "Yo, el infrascripto notario, haviendo sido requerido con el anterior auto-despacho, acepto la comisión que por él se me confiere..." (AEDMB. Fondos órdenes militares. Orden de Santiago leg. 29, exp. 1598). En otro caso similar, sin embargo, se emanó una comisión (AEDMB. Fondos órdenes militares. Orden de Santiago leg. 8, exp. $n^{\circ} 528$ ).

8. Archivo diocesano de Salamanca (ADS), Provisorato, 6-71 (1605), f. 225r.

9. ADS, Provisorato, 44-21 (1644).

10. Esto se confirma en la documentación existente en los archivos privados. Por ejemplo: Biblioteca Pública de Cáceres. Archivo de las familias Rocha, Figueroa y Argüello Carvajal: $2 / 23176-2 / 23654^{a}$. 
documental. Esto no tuvo, aparentemente, grandes complicaciones en las oficinas episcopales. Desde la Edad Media, determinados tipos correspondieron a negocios o materias concretos ${ }^{11}$. Como veremos, algunos de aquellos, como los títulos de órdenes, mantuvieron las características previas durante la Edad Moderna $^{12}$. En estos últimos, la pervivencia de los elementos medievales afectó no solamente a sus caracteres internos sino también a los externos, como la lengua en que se redactaron, esto es, el latín que fue relegado a los documentos relacionados con las órdenes, como las reverendas, al menos en el caso de las diócesis castellanas. De cualquier forma, a lo largo del periodo estudiado hubo, a este respecto, algunos cambios importantes, de modo que el soporte elegido para escriturarlos fue, desde principios del siglo XVII, el papel ${ }^{13}$. La misma pervivencia de usos medievales se observa, en general, en los propios formularios ${ }^{14}$.

Los decretos contienen la iussio, dando indicaciones sobre el documento elegido para comunicar las resoluciones e, incluso, algunas de sus cláusulas. En el caso del beneficio adjudicado a Juan Arias Cabañas en 1743, por ejemplo, se ordenó "... librar título a su favor con recudimiento de frutos..." En otros instrumentos otorgados con idéntico objetivo se estableció que se insertasen las escrituras del procedimiento, extremo que se constata en los del siglo XVIII:

mando se despache separado a su favor el correspondiente título de colación, con mandamiento de posesión y recudimiento de frutos y con inserción de dicha real cédula de la junta apostólica... ${ }^{16}$.

11. Véase, por ejemplo, el caso de las litteras de tonsura o, en general, de órdenes en: María Milagros CÁRCEL ORTí: "Ad servicium Ecclesiae dedicandi. Clérigos aragoneses ordenados en Valencia en el siglo XV", Aragón en la Edad Media, 16 (2000), pp. 163-164. La estructura de este documento coincide con la que exponemos a continuación. Sobre los caracteres externos de los documentos episcopales granadinos, véase: Rafael MARÍN LÓPEZ: "Diplomática eclesiástica granadina", p. 176, quien afirma que el pergamino se empleó únicamente en documentos específicos y el uso del latín fue restringido.

12. María Milagros CÁRCEL ORTÍ: "Notas de Diplomática episcopal: títulos de órdenes sagradas", Hispania Sacra, 45 (1993), pp. 429-458.

13. María Milagros CÁRCEL ORTí: "Notas de diplomática episcopal: reparación de dos letras de tonsura", Saitabi: revista de la Facultad de Geografía i Història, 59 (2009), pp. 211-230.

14. Como veremos se impuso la forma de littera, si bien tanto el preámbulo como la salutatio, que aparecen en los documentos medievales descritos en las diócesis aragonesas, se detectan raramente en los tipos que describiremos a continuación (Pilar PUEYO COLOMINA: "Licencias para pedir limosnas, con o sin indulgencias, otorgadas por los arzobispos de la diócesis de Zaragoza en la segunda mitad del siglo XIV", Aragón en la Edad Media, 16 (2000), pp. 683-708).

15. AEDMB. Fondos órdenes militares. Orden de Santiago, leg. 53, exp. $\mathrm{n}^{\circ}$ 1356. Otro tanto ocurría en las sentencias que saldaban los procedimientos relativos a las capellanías (AEDMB. Fondos obispado, leg. 61, exp. 358).

16. AEDMB. Fondos obispado, leg. 39, exp. s/n. 
En la resolución que zanjó el concurso de curato de la parroquia de Alconchel, otorgada en 1664 por el obispo de Badajoz, se ordenó que se diese un: "despacho colación en la forma ordinaria..."17. En un decreto relativo a una licencia se indicó: "se les dé licencia en forma para pedir limosna entre las buenas gentes para ayudar a pasar su camino, con recomendación para los señores obispos, arzobispos y prelados por donde pasaren" $^{\prime 18}$.

Tras ello venía el "ensayo", materializado en uno o varios borradores, que en las oficinas reales fueron corregidos. Estos sirvieron, en principio, para escriturar el mundum, que podemos entender como el documento puesto en limpio con todas sus cláusulas desarrolladas y en el soporte en que se expediría. Solamente carece de los signos de validación y de la fecha. Para realizar estas acciones, tanto los notarios titulares como los secretarios contaron con auxiliares ${ }^{19}$. En Badajoz, el más importante de estos fue el oficial mayor de secretaría, cargo que ocupó a finales del siglo XVII, durante dieciocho años, Francisco Martínez Ramos, a las órdenes del secretario episcopal Miguel de Bascarán, quien fue canónigo de la catedral de Badajoz ${ }^{20}$. En dicha época el cargo principal de dicho órgano estuvo ocupado por otros beneficiados del cabildo, como el vicario de Tudía. No resulta extraño, pues, que se detecten varias manos en las escrituras, particularmente en los decretos, una circunstancia que se evidencia al comparar la escritura de quien asentó el mundum con las suscripciones correspondientes a los notarios titulares presentes en los borradores a los que hemos aludido anteriormente.

En ocasiones, dicho mundum fue enmendado e, incluso, cancelado en su totalidad. Aunque existen pocos testimonios de ello, se observa la presencia en uno de ellos de una anotación del provisor Francisco Rodríguez de la Madrid, resultado de la recognitio, indicando los cambios que el notario hubo de introducir. Se observa que el tenor de dicho documento, correspondiente a una licencia, se asentó en limpio en su totalidad, con la salvedad de los signos de validación. Se incluyeron, asimismo, tanto el brevete como la tasa correspondiente $^{21}$. ¿Significa esto que se omitió la elaboración de un borrador? El fenómeno detectado en este caso bien pudo ser la norma. A este respecto, hemos de tener en cuenta que los notarios de la audiencia ejercieron su labor durante

17. Ibidem, leg. 30, exp. $\mathrm{n}^{\circ} 7$.

18. ADS, Provisorato, 21-20 (1620).

19. María Milagros CÁRCEL ORTÍ: Vocabulaire international de la Diplomatique, Valencia, Universidad de Valencia, 1997, p. 69.

20. AEDMB. Fondos órdenes militares. Orden de Santiago, leg. 75, exp. $\mathrm{n}^{\circ}$ 2000. De acuerdo con su testimonio, expedido en 1703. A la sazón, dicho Ramos era, además de notario apostólico y ordinario secretario del deán y cabildo y caballerizo de Marín de Rodezno (ibidem).

21. AEDMB. Fondos obispado, leg. 92, exp. 70. 
periodos prolongados, puesto que fueron propietarios de sus oficios, de modo que sus usos se extendieron en el tiempo 22 .

Hemos de considerar que el formulario de los diferentes instrumentos estuvo bien definido. Asimismo, las notas que hemos referido anteriormente facilitaron la tarea de expedición documental. Como hemos señalado, fueron redactadas, en ocasiones, por el responsable de la actio y, otras veces, por los notarios. A esto debemos unir los formularios ${ }^{23}$. Algunos de los tratados de Derecho canónico más difundidos en la época contuvieron las fórmulas de los instrumentos más frecuentes. Por otro lado, en los archivos estudiados se custodiaron originales o copias simples de algunos de los tipos corrientes, que fueron utilizados con idéntico fin. Finalmente, la emanación de algunos instrumentos fue facilitada por el hecho de que sus cláusulas fijas fueron impresas. Esto se detecta tanto en las licencias de confesión, como en los instrumentos relacionados con las órdenes, particularmente las reverendas e, incluso, las publicatas de las ordenaciones, circunstancia que afectó a diferentes diócesis.

Tras esto, el mundum se validó mediante las firmas pertinentes y, en su caso, mediante la aposición del sello. Aquellas fueron las del obispo o su vicario general-provisor u otro delegado ${ }^{24}$. En cuanto a la suscripción del primero, hay que notar que contuvo en el siglo XVI la inicial de su nombre y, a continuación, una referencia al cargo, siempre en latín, a lo que se sumó una rúbrica. Posteriormente, se redujo a su nombre de pila y el título episcopal en castellano, con la salvedad de los documentos redactados en latín. A lo anterior se sumó el refrendo del secretario episcopal o del notario correspondiente.

En cuanto a los sellos, podemos decir que en la época que nos ocupa fueron de tipología heráldica, placados al pie del instrumento correspondien$t^{25}$. Estos dejaron de tener forma de naveta, de modo que fueron ovalados o redondos. En el siglo XVIII aparecen los primeros ejemplos de sellos de estampilla. Estos se usaron, por ejemplo, en el episcopado de Alonso Solís y Grajera, y los encontramos en escritos relacionados con los trámites, más

22. Esto ocurrió, por ejemplo, en Salamanca: ADS, Provisorato, 31-167bis.

23. Esto ocurrió particularmente con los documentos judiciales: utriusque fori causarum cum actionum formulis sermone hispano composita et ad hodiernum stylum accommodata traduntur et ordinatu, Madrid, 1770. Si bien hubo tratados donde se incluyeron fórmulas de algunos de los documentos que estudiamos.

24. Esto se comprueba en algunos decretos que el notario encargado del expediente no llegó a suscribir y donde, sin embargo, aparece la suscripción del provisor (AEDMB. Fondos órdenes militares. Orden de Santiago, leg. 1140, exp. $n^{\circ}$ 38383). Otro tanto se observa en los mandatos: AEDMB. OSA, leg. 1140, exp. no 36383.

25. Una aproximación a la heráldica episcopal reciente en: Gonzalo J. HERREROS MOYA: Heráldica, sociedad y patrimonio. Los obispos de Córdoba, su origen social y escudos de armas (siglos XIII-XXI), tesis de doctorado, Córdoba, Universidad de Córdoba, 2020. 
concretamente en las comisiones ${ }^{26}$. Incluso, se observa que, a finales de dicha centuria, el sello estuvo impreso, como otras cláusulas fijas del tenor documental, como se puede comprobar en las reverendas otorgadas por los priores santiaguistas $^{27}$.

Algunos provisores emplearon sellos propios, una circunstancia para la que no hemos encontrado explicación. Estos fueron anepígrafos y, asimismo, de tipo heráldico ${ }^{28}$. En cuanto a las armas, cabe pensar, a priori, que coincidieron con las del obispo, si bien el estudio de los sellos revela que no siempre fue así. Frente al del prelado, los de los "oficiales" estaban timbrados, en ocasiones, con un yelmo y una cimera ${ }^{29}$.

La situación fue, en cambio, diferente en el caso del priorato de León. En efecto, los de los provisores santiaguistas tuvieron una mayor uniformidad, si bien hubo variantes puntuales a lo largo del periodo estudiado. En su campo apareció, sistemáticamente, un león rampante sobre una cruz de Santiago y estuvieron timbrados por un capelo con seis bordones. Fueron anepígrafos, con la salvedad de los emanados por el prior, como puede se comprueba en el caso de las requisitorias más tardías, si bien a lo largo del siglo XVII emplearon, aparentemente, el mismo que sus provisores. En todo caso, en ellos no aparecen ni báculo ni llaves, así como tampoco una cruz o mitra.

\subsection{La tasación de los documentos}

Dada la escasez de los registros de la secretaría episcopal que se han conservado no podemos reconstruir con exactitud cómo se verificó el cobro de las tasas, si bien es cierto que estas se regularon en los aranceles episcopales. A este respecto, cabe decir que se pagaron dos tipos de derechos. En primer lugar, los correspondientes al sello y, por otro lado, los relativos al trabajo de los escribas, esto es, los notarios o el secretario. Dichas cantidades se anotaron en los registros de las cancillerías episcopales medievales, al principio, de un modo dubitativo y, más tarde, de forma más o menos sistemática. En este últi-

26. AEDMB. Fondos obispado, leg. 41, exp. $n^{\circ} 1543$. Otro documento del mismo tipo expedido por el mismo obispo en: ibidem, leg. 97 , exp. $n^{\circ} 43$; ibidem, leg. $n^{\circ}$ 5, exp. $n^{\circ} 78$; ibidem: leg. 1141, exp. $\mathrm{n}^{\circ}$ 1143. Los priores de la orden Alcántara emplearon dicho sello para validar sus reverendas (AEMB. Fondos obispado. Caja de órdenes, 1798, exp. s/n).

27. AEDMB. Fondos obispado. Caja de órdenes, 1798, exp. s/n.

28. María Luisa CABANES CATALÁ, Vicente Ramón BALDAQUÍ ESCANDELL: "Sigilografía episcopal orcelitana de los siglos XVI y XVII en el Archivo Municipal de Elche", Actas del primer Coloquio de Sigilografía. Madrid 2 al 4 de abril de 1987, Madrid, 1990, pp. 309-316.

29. Por ejemplo: AEDMB. Fondos Obispado, caja 3119, exp. no 8025; ibidem, caja 3720, exp. $\mathrm{n}^{\circ}$ 1004. Tampoco coinciden los empleados por los provisores Gabriel Ortiz o Juan Ramos Lorenzana con sus obispos respectivos: idem, caja 3065, exp. 6087; y otro tanto en el caso de José de la Cerda (idem, caja 3770, exp. s/n). 
mo momento, las omisiones se debieron, en ocasiones, a que su pago no fue uniforme, circunstancia que dependió de la condición de los individuos o de sus posibilidades económicas. A su vez, hubo diferencias notables entre los documentos: en algunos no se cobró tasa alguna y, otras veces, las cantidades no fueron idénticas ${ }^{30}$.

Esta situación se prolongó en el tiempo. En efecto, las licencias de confesión otorgadas en Badajoz o en el priorato de León estuvieron exentas de pago, como se evidencia en los propios instrumentos. La explicación de esta situación se puede rastrear en algunos memoriales de la época. Uno de ellos, anónimo, conservado en los fondos de la Biblioteca Nacional, se presenta como una respuesta a otro escrito donde se defendió que los secretarios no cobrasen nada por escrituras como títulos de confesor, licencias para administrar sacramentos, servir beneficios, administrar misa, ausentarse, sepultarse en iglesia o, finalmente, publicatas de ordenandos. Si bien, a la luz de los cánones tridentinos, quedó claro que el obispo no podía percibir ningún derecho por ello, con el fin de evitar que recayese sobre él la sospecha de simonía, los secretarios percibieron una tasa, particularmente si carecieron de salario ${ }^{31}$. En otros documentos, siempre y cuando las tasas fuesen moderadas, no hubo dicho impedimento ${ }^{32}$. Se estableció, asimismo, que las licencias para pedir limosna debían ser gratuitas, puesto que, en caso contrario, se verificaba una demanda excesiva para los afectados ${ }^{33}$. En cuanto a las licencias para predicar otorgadas a los regulares, el concilio de Trento estableció que fuesen gratis frente a las de los seculares, de modo que el secretario debía cobrar una tasa ${ }^{34}$.

\subsection{El registro de los documentos}

No conservamos, para el periodo estudiado, los registros de la secretaría episcopal pacense, con la salvedad del correspondiente al año 1676, perteneciente al obispo fray Agustín Antolínez. Este consta de varios cuadernos. Al principio de él aparece un índice donde figuran los asientos, ordenados por negocios jurídicos ${ }^{35}$.

El hecho de que se haya conservado dicho documento se debió, probablemente, a que fue reutilizado para asentar las ordenaciones de 1689 . Como se puede comprobar observando el índice que hemos señalado, no

30. María Milagros CÁRCEL ORTí: “Las tasas de la cancillería valentina y el 'gratis' en los registros del obispo Hugo de Llupià (1408-1425)", Analecta Sacra Tarraconensia, 72 (1999), pp. 55-108.

31. Biblioteca Nacional, mss/18242, ff. 60r-60vo.

32. Ibidem, f. 62 vo.

33. Ibidem, f. 55vo.

34. Ibidem, f. 57r.

35. AEDMB. Fondos obispado, leg. órdenes I, año 1680-1699, s/n. 
aparecen los títulos de órdenes expedidos en 1676. Esto se debió, probablemente, a que se dejó constancia de ellos en libros de "matrícula de órdenes" o "registra ordinatorum" ${ }^{36}$. A este respecto, como veremos a continuación, cabe destacar que en los títulos de órdenes del siglo XVIII aparece, sistemáticamente, la nota de registro, de modo que debió existir en dicha época este último.

El vacío señalado no solamente se debió a la destrucción sufrida por el archivo episcopal durante la Guerra de Independencia. Aparentemente, al menos hasta la segunda mitad del siglo XVII, algunos obispos se llevaron la documentación correspondiente a los trámites en los que participaron cuando abandonaron la diócesis. En 1669 el licenciado Antonio Trigo, electo como cura de Alconchel, solicitó que se le diese el título de colación para tomar posesión de dicho beneficio. Para comprobar la certeza de dicha reclamación, ante la aparente ausencia pruebas documentales, los canónigos que participaron en el concurso de dicho curato declararon que participaron en los trámites correspondientes, que tuvieron lugar en los palacios episcopales el 14 de mayo de 1668, bajo la supervisión del obispo Jerónimo Rodríguez de Valderas, electo por aquel entonces para ocupar el obispado de Jaén. Tras esto, el referido Trigo "... sin tener la colación del dicho curato, ni sacar los despachos... se ausentó de la ciudad, a buscar y traer dinero para los gastos y, cuando volvió allá, el dicho señor obispo se había ido de este obispado al de Jaén...". Los testigos, entre los que se contó el canónigo Juan Solano Figueroa, afirmaron tener "... por cierto y sin duda que el señor obispo se conformó con el parecer de dichos señores examinadores..." 37 .

Esto no implica que no hubiese registros. Frente a lo afirmado en trabajos centrados en el siglo XVI, donde se establece la omisión de dicha tarea por parte de la secretaría episcopal ${ }^{38}$, se detecta su presencia en las cancillerías episcopales medievales, más particularmente aragonesas y podemos entender que la situación no debió ser diferente en las diócesis de Castilla ${ }^{39}$. Hay noticias sobre la obligación de los notarios de las audiencias episcopales de mantener

36. Saul ANTONIO GOMES: "As 'matrículas de ordens': de elemento diplomático a acontecimento histórico. Subsídio para o estudo do clero português no final dos tempos medievos", Lusitania Sacra, 13-14 (2001-2002), pp. 229-266. Véase también: María Milagros CÁRCEL ORTÍ: "Notas de diplomática episcopal...".

37. AEDMB. Fondos obispado, leg. 53, exp. $\mathrm{n}^{\circ} 9$.

38. Rafael MARÍN LÓPEZ: "Diplomática eclesiástica granadina".

39. María Milagros CÁRCEL ORTí: "Un registro de colaciones del obispo de Valencia Jaume d'Aragó de 1383", Analecta sacra tarraconensia: revista de ciencias histórico-eclesiásticas, 89 (2016), pp. 1213-246. De la mis autora: "Un registro de colaciones de Hug de Fenollet y Vidal de Blanes, obispos de Valencia (1350-1359)", Estudis castellonencs, 9-2 (2000-2002), pp. 599-772. "Los registros episcopales", en Elena CANTARELL BARELLA y Mireia COMAS (coord.): La escritura de la memoria: los registros, Barcelona, Promociones y publicaciones universitarias, PPU, 2011, pp. 133-148. 
registros de las disposiciones de los provisores. Esto se manifiesta en numerosas constituciones sinodales, como las de Palencia donde, para evitar las pérdidas anteriores se decretó lo siguiente:

... establecemos que nuestro secretario o notarios ante quien pasaren los autos de las dichas órdenes sean obligados a hacer y hagan dos registros de todos los que fueren ordenados en manera que hagan fe, firmados de los nuestros examinadores y el uno de ellos quede en poder del notario y el otro se ponga en el archivo donde están las escrituras de nuestra iglesia ${ }^{40}$.

La situación de los fondos santiaguistas es diferente, puesto que se localizan registros de colaciones de beneficios. En ellos se incluyeron copias de los títulos correspondientes a los curatos o las capellanías.

En cualquier caso, hemos de tener en cuenta que hubo diferentes medios de conservar la memoria de las resoluciones. En este sentido, los fondos episcopales evidencian un fenómeno frecuente en otros archivos de la Edad Moderna, esto es, la multiplicación de fondos y la existencia de documentos diferentes donde se asentó la misma disposición. De este modo, los nombramientos de las obras pías se inscribieron en los libros de administración de estas: "... mando se ponga nombramiento en el libro de dicha obra pía en la forma de estilo, a favor de la referida y se le dé certificación de él para su resguardo" ${ }^{41}$; o también: "anotándolo en el protocolo para que siempre conste $^{\prime \prime 4}$. En las escrituras de censo conservadas en el archivo estudiado en este trabajo aparecen anotaciones relativas a los trámites y cambios producidos en la gestión de las propiedades. Asimismo, se ordenó que se incluyese en dichos contratos una copia de los documentos relativos a la tramitación: "otorgándose por dicha Isabel escritura de imposición con traslado de estos autos..." 43 . Por otro lado, de la exención de las amonestaciones para casarse se dejó constancia tanto en los libros parroquiales como en la cancillería episcopal, donde se remitieron los autos correspondientes ${ }^{44}$.

40. Constituciones sinodales del obispado de Palencia ordenadas por mandado del ilustre y reverendísimo señor don Luis Cabeza de Vaca, obispo del dicho obispado, Conde Pernía, s. I., s. d, p. 56. Otro tanto se estableció en el caso de la diócesis de Valladolid (Constituciones synodales fechas y promulgadas en la primera sínodo que se celebró en la ciudad y obispado de Valladolid por el ilustrísimo y reverendísimo señor don Juan Baptista de Azevedo, patriarca de las Indias, segundo obispo del dicho obispado e inquisidor apostólico general en los reynos y señoríos de su Magestad. Valladolid 1607, p. 49).

41. AEDMB. Fondos obispado, leg. 9, s/n.

42. AEDMB. Fondos órdenes militares. Orden de Santiago, caja 521, exp. 13951.

43. AEDMB. Fondos obispado, leg. 17, exp. 230; ibidem, leg. 3, exp. 32.

44. Ibidem, leg. 59, exp. $\mathrm{n}^{\circ} 1473$. 


\section{La estructura diplomática. Características básicas}

En lo que respecta a las estructuras diplomáticas de los tipos documentales que estudiamos, cabe decir que, con la excepción de los decretos o de las certificaciones expedidas por notarios o secretarios para comunicar las decisiones de las autoridades, correspondieron a la de carta o littera, bien definida en la Edad Media en la documentación episcopal ${ }^{45}$.

En cuanto a su tenor, hemos de destacar, en primer lugar, la invocatio, que se reduce a una cruz. A continuación, encontramos la intitulatio que tiene diferentes formas. En el caso del obispo, como en los instrumentos medievales, en la primera se hace alusión al nombre, la calidad y la condición del autor, precedido, en su caso, por el pronombre "nos" que, en los documentos del siglo XVIII del prior santiaguista fue reemplazado por "yo", a lo que siguió el tratamiento "don" o "dominus" en latín ${ }^{46}$. Tras esto se añade la expresión de derecho divino: "por la gracia de Dios y de la santa Sede apostólica obispo de...", "por la gracia de Dios y de la santa Iglesia de Roma obispo de...". En latín la fórmula correspondiente es: "Dei et Apostolica Sedis gratia episcopus...". A continuación, se alude a la diócesis y, tras ello, se refieren otros cargos de su titular, como la pertenencia a uno de los consejos de la Monarquía o el oficio de confesor real, si bien tanto estos como otros se elidieron, con frecuencia, mediante la expresión "etcétera" ${ }^{47}$. Así, por ejemplo:

Nos, frey Dominus Franciscus Xaverius Calderón de la Barca ZevaIlos Prior Magazelensis, totiusque Provincia de la Serena cum Heliche et Castilleja, ordinis Militiae de Alcantara, nullius Dioecesis nec intra fines alicuius Dioecesis sub regula Domini Benedicti constitutus judex conservator regalis Monasterii Sancta Maria de Guadalupe, ordinis Domini Hieronymi, praedictaeque militae generalis visitator, regiusque consiliarius, et caetera ${ }^{48}$.

Dominus loannes Marín a Rodezno, Dei et appostolicae sedis gratia episcopus pacensis, regiusque consiliarius et caetera.

En el apéndice se pueden observar varias muestras de ello en romance. Por regla general, dicha intitulatio fue sustituida, en el caso de los decretos, por otra de carácter más simple, que consiste en una simple alusión al cargo detentado por el autor del documento, por ejemplo: "el obispo de Badajoz" o, en su caso, el nombre y la prelacía.

45. María Milagros CÁRCEL ORTí: Un formulari i un registre del bisbe de València en Jaume d'Aragó (Segle XV), Valencia, Universidad de Valencia, 2005.

46. AEDMB. Fondos órdenes militares. Orden de Santiago leg. 65, exp. 820.

47. En este sentido, cabe apuntar la referencia a la titularidad del cargo de vicario general del Real Ejército de Extremadura que aparece en la intitulación de los obispos pacenses del siglo XVIII.

48. AEDMB. Fondos órdenes militares. Orden de Santiago, caja 2304. 
En cuanto a la intitulatio del provisor y vicario general, cabe distinguir, como en el caso anterior, dos tipos, cuyo uso correspondió a los mismos tipos documentales que expidió el obispo, con la salvedad de los títulos de órdenes o las dimisorias, puesto que dichos oficiales carecieron de la potestad de administrar el sacramento correspondiente. Cabe señalar que, tanto en los del siglo XVIII, la intitulatio se separó del resto del documento y se destacó, además, mediante una letra de módulo diferente, siendo precedida por el pronombre "nos" en el caso de los provisores santiaguistas o "don" en sus homólogos pacenses ${ }^{49}$. En ella se refieren: el nombre, el grado académico, así como el cargo ostentado: "provisor y vicario general de la diócesis...". A continuación, se señala, si bien se omite con frecuencia, la fuente de la autoridad vicaria: "por su señoría, don Diego Gómez de la Madriz, obispo del dicho obispado del Consejo de su Majestad". A esto se añade una referencia a otros cargos, particularmente el de "abogado de los consejos reales". Frente a lo referido, tenemos una intitulatio más simple en la que se hace referencia únicamente al oficio, que se empleó en los decretos.

La directio, con frecuencia, está implícita en la expositio.

Respecto a la salutatio, podemos decir que no hay una norma general para ella, si bien se usó raramente. Es fija en las reverendas: "salutem et sinceram in domino benedictionem", "salutem in Domino", una circunstancia nada extraña, dado el "conservadurismo" que mantuvo, como veremos con más detalle, su formulario. En cuanto a las fórmulas en romance, la más común es: "salud y gracia", o "salud en nuestro señor Jesucristo".

Hemos de destacar, además, la eliminación de la arenga o preámbulo. En lo que respecta a la notificatio, junto a las expresiones latinas típicas a las que nos referiremos más adelante, se emplearon otras romances, coincidentes con las de la documentación real: "hacemos saber". En relación con la expositio no se puede establecer una norma general, si bien corresponde, como veremos, a los requisitos establecidos por la tratadística de la época y ciertas expresiones son recurrentes en ella. El dispositivo, que trataremos con más detalle a continuación, tiene relación directa con el negocio jurídico.

La sanctio es variable y depende del tipo documental. Las cláusulas que podemos encontrar son las siguientes:

- Cláusula de salvaguarda. Típica de las licencias o de los títulos de oficial, relacionada con la revocabilidad de dichas disposiciones: "... durante el tiempo de nuestra voluntad pueda ejercer dicho cargo en los casos y cosas a él tocantes y pertenecientes..."; "por el tiempo que fuere nuestra voluntad"50. Esto implicó que la concesión estuvo en vigor has-

49. AEDMB. Fondos órdenes militares. Orden de Santiago, leg. s/n.

50. Ibidem, leg. 382, exp. $\mathrm{n}^{\circ} 16172$. 
ta la muerte o cese de la autoridad, salvo que esta escogiese anularla antes $^{51}$. Sin embargo, hubo otorgamientos hechos por un tiempo determinado.

Dicha cláusula se relaciona también con el derecho de los obispos de la época de absolver de los casos reservados, así como los correspondientes a otras instancias: "excepto de los reservados a la santa sede apostólica, al santo Oficio de la Inquisición y a nos, como ordinario" ${ }^{\prime 52}$.

También aparece en las licencias de predicación: "sin perjuicio del derecho parroquial"; "con permisión del cura o curas del pueblo o pueblos donde los administrare" 53 ; "con licencia de los curas de las iglesias donde lo hiciere y sin perjuicio del derecho parroquial...". No era fija y se observa su omisión en los documentos santiaguistas del siglo XVII.

- Cláusula preceptiva. Aparece en los títulos beneficiales, incluso en las tenencias de curato, reforzándose, en su caso, con una cláusula penal:

mandamos... que cualquiera clérigo notario que con este fuere requerido vos ponga y asiente en la posesión de la dicha capellanía por los libros y ornamentos y cuerdas de campanas de la dicha iglesia, lanzando y quitando cualquier ilícito detentor, si le ende hubiere.

En los instrumentos beneficiales más antiguos de la diócesis de Badajoz se reforzó con una cláusula penal y fue:

... mando, en virtud de santa obediencia y, so pena de excomunión mayor, a los venerables curas, clérigos, capellanes, sacristanes, notarios apostólicos, escribanos reales de esta dicha ciudad e a cada uno e cualquier de ellos que, luego que con esta mi carta de colación fueren requerido o requeridos, os metan e hagan meter en la tenencia e posesión real, corporal, actual civil vel casi de la dicha capellanía e bienes a ella dotados anexos e pertenecientes y que pertenecer puedan en cualquiera manera vos amparen e defiendan en la dicha posesión y vos hayan e tengan por tal capellán de la dicha ${ }^{54}$.

51. Alonso de VEGA: Espejo de curas, utilísimo para todo género de eclesiásticos, y principalmente para aquellos que tienen cargo de ánimas, por comprenderse en él todo lo que les es necesario para cumplir con la obligación que tienen, Madrid, Francisco de Robles, 1602, pp. 308-9.

52. AEDMB. Fondos órdenes militares. Orden de Santiago, leg. 70, exp. $\mathrm{n}^{\circ} 890$.

53. Ibidem, leg. 220, exp. $\mathrm{n}^{\circ} 7564$.

54. Biblioteca pública de Cáceres. Archivo de las familias Rocha, Figueroa y Arguello Carvajal: 2/23176-2/23654A. 
En las licencias para oficiar misa su formulación es: “... mandamos a todos los curas y sacristanes de esta nuestra diócesis le hagan dar y den el recado para ello, sin ponerle impedimento ni embarazo alguno" ${ }^{\prime 55}$.

- Cláusula de otorgamiento de poder: típica de los títulos de oficial, si bien no es fija en ellos: "vos damos poder cumplido", "y le damos poder y facultad la que por derecho se requiere..."

- Cláusula penal. Se trata, generalmente, de la excomunión: “... mando, en virtud de santa obediencia y so pena de excomunión mayor", aunque también se pueden añadir penas pecuniarias: "pena de excomunión mayor y de cuatro mil maravedíes, aplicados conforme a derecho y con apercibimiento que, además de las dichas censuras y penas, se procederá a las demás que haya lugar contra el que fuere rebelde..." ${ }^{57}$. Se detecta, menos frecuentemente, otra de carácter genérico, que hace alusión a las sanciones establecidas en determinados ordenamientos canónicos: "debajo de las penas que en dichas constituciones se contienen" ${ }^{\prime \prime 8}$.

- Cláusula prohibitiva: “... contra lo concordado no vayan ni consientan ir en manera alguna..." 59 ; “... que no usen de ellas ni ejerzan el dicho ministerio de confesores" ${ }^{\prime \prime}$.

- Cláusula conminatoria. Típica de los beneficios: señala la obligación de acudir con sus frutos al titular. En los títulos otorgados en el priorato santiaguista de León no se constata su presencia hasta finales del siglo $\mathrm{XVI}$, al contrario de lo que ocurrió en Badajoz, donde fue habitual en ese momento:

... mando a los arrendadores, censualistas, poseedores, inquilinos, tenedores de los dichos bienes anexos pertenecientes y dotados a la dicha capellanía, que vos den y acudan y hagan dar y acudir con todos los dichos bienes y con los frutos, rentos, réditos y obvenciones a la dicha capellanía, dotados habidos y pertenecientes y que pertenecerle puedan en cualquier manera sin que falten de cosa alguna.

- Cláusula derogativa. No es común: "el cual le modera y reforma su ilustrísima en lo que toca a la información de limpieza de sangre, por los gravísimos inconvenientes que se experimenta de semejantes estatutos y mandaba y mandó se omita dicha información para con todos los pretendientes y que solo se haga la de buena vida y costumbres y luego se pase

55. AEDMB. Fondos obispado, leg. 64, exp. $\mathrm{n}^{\circ} 41$.

56. AEDMB. Fondos órdenes militares. Orden de Santiago, leg. 382, exp. no 16172.

57. AEDMB. Fondos obispado, leg. 65, exp. $n^{\circ} 398$.

58. Archivo catedralicio de Salamanca (ACS), 396-23.

59. AEDMB. Fondos obispado, leg. 65, exp. $\mathrm{n}^{\circ} 398$.

60. Ibidem, leg. 495, exp. $\mathrm{n}^{\circ} 19136$. 
a votar la admisión por toda la cofradía, como se estilaba hasta ahora, con la circunstancia de que se vote secretamente con habas blancas y negras $^{\prime \prime 61}$.

- Cláusula de cumplimiento: “... y para que les pare entero perjuicio se notifique a quien se dirige y se ponga por $\mathrm{fe}^{\prime \prime 62}$, "... y, so la misma pena, el cura de la dicha villa se lo notifique" ${ }^{\prime 63} ;$ " ... dentro de seis días nos remitan... testimonio de haberse publicado los dichos mandatos y notificado a las dichas monjas, so las dichas censuras" ${ }^{\prime \prime 4}$. Aunque no se señalase expresamente, el encargado de la diligencia debía consignarla en el pie o en el vuelto de los documentos, como se observa en los conservados: " $y$, dentro de seis días, nos remitirán las dichas licencias que así recibieren los dichos curas y tenientes y testimonio de haberse publicado los dichos mandatos y notificado a las dichas monjas, so las dichas censuras..."65.

- Cláusula de obligación. Es típica de las reverendas concedidas solamente por la autoridad episcopal, si bien no es fija. Asimismo, al detectamos en las testimoniales: "ofreciéndonos al tanto en recíproca correspondencia" ${ }^{\prime \prime 6}$.

En cuanto a la corroboratio no hay tampoco una norma fija. Respecto a la validatio, cuenta, como hemos visto, con la firma del autor, a la que acompaña el refrendo del notario o secretario. Igualmente, podemos encontrar entre los signos de validación el sello, si bien se detectan irregularidades respecto a esto último, como veremos a continuación.

\section{Los tipos documentales}

\subsection{Decreto ${ }^{67}$}

Pese a que, como hemos visto, hubo desde un punto de vista procedimental, dos tipos de decreto, si bien dicha circunstancia no afectó a su tenor, que se inspiró en la de los autos judiciales. No es extraño, pues, que ambos recibiesen

61. ADS, Provisorato, 396-23. El estatuto de limpieza de sangre no estuvo presente en otras instituciones de la diócesis salmantina, como el cabildo catedralicio (José Ignacio TELLECHEA IDÍGORAS: "El cabildo catedral salmantino ante el estatuto de limpieza de sangre: historia de una doble tentativa fallida (1548-1559)", Salmaticensis, 33-3 (1986), pp. 345-369).

62. AEDMB. Fondos obispado, leg. 65, exp. n 398.

63. AEDMB. Fondos órdenes militares. Orden de Santiago, leg. 918, exp. n 31088.

64. Ibidem, leg. 495, exp. no 19136.

65. Ibidem, leg. 485 exp. no 19136.

66. AEDMB. Fondos órdenes militares. Orden de Santiago, leg. 101, exp. s/n.

67. Una transcripción de este tipo en: Francisco Luis RICO CALLADO: "La documentación gubernativa diocesana en la Edad Moderna a través de los expedientes de concursos de beneficios curados", Ibersid: revista de sistemas de información y documentación, 11-1 (2017), pp. 51-62. 
el mismo calificativo en la época. Constituyó, en general, un "brevísimo indicio" donde en, escasas palabras, la autoridad dirimió la cuestión planteada. En general, cabe destacar su simplicidad, aunque algunos, como aquellos en los que se autorizó el otorgamiento de los contratos de censo, son más complejos, puesto que contienen directrices sobre los términos de dichos pactos ${ }^{68}$.

Data tópica y crónica.

Intitulatio.

Expositio, se expresaba la motivación del auto y, asimismo, se podían insertar cláusulas de procedimiento, que se pueden asimilar a las empleadas en los documentos judiciales: “... en atención a lo que de todo resulta y a que dicha renuncia es libre y de su espontánea voluntad y a que no interviene dolo, fraude, engaño, simonía ni otro algún pacto reprobado por derecho" ${ }^{69}$; "cuanto puede y ha lugar por Derecho, en atención a ser libre y de su espontánea voluntad, sin intervención de dolo, fraude, simonía ni otro algún pacto reprobado por derecho y teniendo cumplidas sus cargas hasta ese día..." ${ }^{\prime 70}$.

Dispositio: estaba determinada por la naturaleza del negocio jurídico e introducida por el verbo "dijo": "... la debía de admitir y admitió"71; "declaraba y declaró por acreedora de él", "le concedía y concedió..."; "admitía y admitió la sumisión y obediencia..."72. En las licencias: “... concedía y concedió licencia..."73; " dio licencia a cualquier impresor de libros para que, guardando las premáticas reales, las pueda imprimir ${ }^{\prime \prime 74}$. En los relativos a una renuncia de un beneficio: "admitía y admitió... y lo declaraba y declaró y daba y dio por vacío para proveerlo su señoría Ilustrísima..."75. En los decretos donde se aprobaron o confirmaron reglas de cofradías, la dispositio incluyó un mandato:

confirmaba y confirmó la dicha cofradía y ordenanzas de ella supra escritas y mandó se guarden y cumplan según y como en ellas se contiene, para siempre jamás ${ }^{76}$.

68. Por ejemplo: AEDMB. Fondos obispado, leg. s/n. AEDMB. Fondos órdenes militares. Orden de Santiago, leg. 1409, exp. s/n.

69. Ibidem, leg. 52, exp. $\mathrm{n}^{\circ}$ 3. Ibidem, leg. 117, exp. $\mathrm{n}^{\circ} 33$.

70. AEDMB. Fondos obispado, leg. 52, exp. 3.

71. Idem.

72. AEDMB. Fondos órdenes militares. Orden de Santiago, leg. exp. $\mathrm{n}^{\circ} 1603$.

73. Ibidem, leg. 1409, exp. s/n.

74. ACS, 49-1-32.

75. AEDMB. Fondos obispado, leg. 102, exp. $\mathrm{n}^{\circ}$ 55. Fue otorgado por el obispo Francisco Roís y Mendoza en cuatro de diciembre de 1670.

76. Idem. Otro ejemplo en: ACS, 396-23. 
En los decretos más antiguos, la dispositio se expresó al modo de las sentencias:

fallaba y falló ser justas y sanctas y convenientes a la gobernación y perpetuidad de la dicha clerecía y cofradía. Por tanto, que como tal provisor y juez ordinario las debía confirmar y confirmaba, aprobar y aprobaba y mandó que se guarde y cumpla ahora y en todo y siempre jamás por los dichos abad y clérigos de la dicha cofradía que son y por tiempo fueren ${ }^{77}$.

La directio estaba implícita en el dispositivo. Se señalaban, a continuación, una serie de diligencias o condiciones para que lo dispuesto se ejecutase. En este sentido, en los decretos donde se aprobó un contrato de censo se aludió al tenor que había de tener la escritura correspondiente ${ }^{78}$. Podía darse, asimismo, una orden para asentar el decreto en los libros de administración correspondientes o, en su caso, en las escrituras conservadas en el archivo: "... mando se ponga nombramiento en el libro de dicha obra pía en la forma de estilo, a favor de la referida y se le dé certificación de él para su resguardo"79, "anotándolo en el protocolo para que siempre conste" ${ }^{\prime \prime 80}$.

Sanctio: cláusula penal, reservativa, preceptiva, derogativa, de cumplimiento, prohibitiva. No eran fijas.

Cláusula de corroboración: "Así lo proveyó, mandó y firmó". "Así lo mandó y firmó".

Validatio. Suscripción del provisor u obispo y refrendo del notario, cuya firma iba precedida por la fórmula: "por mandado..." o similares.

77. Aprobación de la hermandad de clérigos de Santa María de los Villares declarada por el licenciado Pedro Velarde, provisor de la diócesis de Salamanca en 15 de febrero de 1554 (ACS, 225-3). Otro tanto se observa, sin embargo, en un decreto emanado por el provisor salmantino unos años más tarde, más concretamente en 1574: “... fallaba y falló que debía usar de las dichas reliquias como de reliquias santas, fasta que otra cosa parezca y se ha mandado y con esto dio licencia a dicho señor don Antonio Vásquez de Coronado y a la señora doña Sancha Rodríguez de las Varillas su mujer, para que puedan usar de ellas..." (ADS, Provisorato, 11-3 (1574)).

78. Los decretos donde se concedía una licencia para hacer obras en las iglesias podían detallar también sus características (ADS, Provisorato, 5-114 (1559)).

79. AEDMB. Fondos obispado, leg. 9, exp. s/n.

80. AEDMB. Fondos órdenes militares. Orden de Santiago, caja 521, exp. $n^{\circ} 13951$. A este respecto, hemos de hacer notar que en el archivo se encuentran numerosas escrituras de censo y de otros negocios donde se anotaban los trámites y cambios producidos en la gestión de las propiedades correspondientes. 
Hay otra variante de este documento, que carece de la forma de acta, de modo que, tras una cláusula de procedimiento, se inserta la intitulatio. El resto del tenor es igual, con la salvedad de que la data aparece al final.

\subsection{La licencia ${ }^{81}$}

Estas se otorgaron por diferentes razones, aunque no fueron siempre fijas. Así, por ejemplo, en el caso del nombramiento del sacristán de la parroquia de San Miguel de Zorita de la Frontera, fechado en 1620, no se emanó un nombramiento sino una licencia. Esto pudo deberse a que el candidato incumplió algún precepto legal o, probablemente, a un uso confuso de los tipos documentales ${ }^{82}$.

Invocatio.

Intitulatio.

Expositio: en el caso de aquellos documentos donde se concedió permiso para administrar sacramentos o predicar, se señaló la pertinencia y la capacidad del destinatario mediante expresiones como: "confiando de la virtud, ejemplar vida y suficiencia". Otro tanto ocurrió con las de celebrar, donde se detallaron no solamente las capacidades del destinatario, sino que, asimismo, se dejó constancia del examen previo: “... por estar bien advertido e instructo en ellas y demás que debe para ello saberse" ${ }^{\prime 83}$; "por cuanto nos consta de la suficiencia de...". En cambio, en el caso de las otorgadas con otros fines, como las destinadas a pedir limosna, la expositio fue más breve ${ }^{84}$.

La directio está implícita en la expositio y contiene el nombre del destinatario, y, en su caso, sus grados académicos, órdenes, vecindad...

Sanctio: cláusula de salvaguarda. No es fija. En el caso de las licencias de confesión, a finales del siglo XVII, se evidencia una novedad, que se incorporó de forma sistemática en los documentos de la centuria siguiente y que consiste en una alusión a los casos reservados al obispo o el Papa. Esto se puede explicar a raíz de las polémicas generadas respecto a la administración de dicho sacramento y, particularmente, de la potestad de las órdenes religiosas. Dicha circunstancia obligó a incluir referencias a la legislación vigente en el tenor y una relación de los casos de los que solamente podía absolver el obispo, organizados en columnas en el pie del documento (apéndice: documento 2).

81. Apéndice documental: documento 1.

82. Posteriormente, en 16 de noviembre de 1631, el visitador renovó el cargo a Bernardino Franco (ADS, Provisorato, 32-152 (1628)).

83. AEDMB. Fondos órdenes militares. Orden de Santiago, leg. 65, exp. ${ }^{\circ} 820$.

84. Ibidem, leg. 101, exp. $\mathrm{n}^{\circ} 4375$ 
Cláusula preceptiva: propia de las licencias para oficiar misa. No es, por tanto, fija.

Corroboratio. Se omite frecuentemente.

Data.

Validatio. Firma del otorgante y refrendo del notario o secretario. En cuanto al sello, hemos de decir que, con frecuencia, no aparece, particularmente en el caso de las licencias de confesión ${ }^{85}$. Por otro lado, el lugar aposición en los documentos del siglo XVI no fue el pie, sino su reverso. Esto se observa en diferentes diócesis, tanto en el priorato de León como en Salamanca ${ }^{86}$.

\subsection{Título de beneficio ${ }^{87}$}

Este tipo documental recibió diferentes nombres, como los de carta de colación o provisión ${ }^{88}$. En los formularios de la época encontramos modelos de este tipo documental. Especialmente significativas fueron las reflexiones de tratadistas como Monacelli o Rebuffe. Este último destacó algunas de sus cláusulas esenciales, como la preceptiva o la corroborativa. Asimismo, insistió en la necesidad de que se aludiese a la causa de la provisión, los bienes y dotación del beneficio, particularmente si se trataba de una capellanía, así como a las cualidades del nuevo beneficiario, esto es, si era "sufficienti, capaci et idoneo ad dictum" 89 . Finalmente, se había de referir la investidura o colación del beneficio, que se efectuó mediante un acto solemne, del que se dejó constancia en las resoluciones que saldaron

85. Ibidem, leg. 495, exp. $\mathrm{n}^{\circ} 19136$.

86. Así, por ejemplo, en el caso de la licencia otorgada por el provisor santiaguista Alvar López Becerra en 18 de abril de 1504 (AEDMB. Fondos de órdenes militares. Orden de Santiago, leg. 18, exp. $n^{\circ}$ 973).

87. Una transcripción de este tipo documental en: Francisco Luis RICO CALLADO: "La documentación gubernativa...", p. 62.

88. Este último calificativo en: Durand de MAILLANE: Dictionnaire de Droit Canonique et de pratique bénéficiale conferé avec les maximes et la jurisprudence de France c'est-à-dire, avec les usages et libertés de l'Église gallicane, les pragmatiques et concordats, les ordonnances, édits et déclarations de nos Rois, les arrêts des Parlements et du Grand-Conseil, les saines opiniones des auteurs français et la pratique des officialités, tomo II, París, Jean Baptiste Bauche, 1759, p. 586.

89. Pierre REBUFFE: Praxis beneficiorum. Lugduni, Guglielmi Rovillii, 1620, p. 21. En Palencia se exigió que los documentos en cuestión incluyesen una "...declaración y apeo de todas sus casas, heredades, posesiones, censo e tributos que tuvieren e quede otro tanto en poder del notario de nuestra audiencia... " (Constituciones sinodales del obispado de Palencia..., p. XXXVIIV). Esto se detecta en algunos títulos expedidos en el priorato de León (AEDMB. Fondos órdenes militares. Orden de Santiago, leg. 30, exp. $n^{\circ} 3772$ ). 
los expedientes. La Iglesia adaptó, a este respecto, algunos de los usos de las instituciones feudales ${ }^{90}$.

En cualquier caso, en la época solamente se adquiría la plena propiedad del beneficio mediante su entrega o posesión, requisito que Bonifacio VIII estableció, por ejemplo, en el caso de los obispos ${ }^{91}$. En este sentido, los canonistas hablaron del "derecho en el beneficio" y del "derecho al beneficio"92. Esta fue la razón por la que en los instrumentos se incluyó, como indicó Pierre Rebuffe, una cláusula preceptiva dirigida a un clérigo o a un notario para que pusiesen en posesión de la prebenda al nominado ${ }^{93}$.

Por tanto, la institución corporal consistió en las formalidades en "... cuya virtud el clérigo recibe los símbolos de su oficio, como en señal de que comienza a ejercerlo" ${ }^{\prime 94}$. Tales diligencias se consignaron en un testimonio ${ }^{95}$. Dichos actos estuvieron cargados de simbolismo. Esto se realizó, en general, entrando en el lugar donde estaba situado el beneficio. Un párroco debía coger el aspersor o bien besar el altar mayor de su parroquia, en los canónigos, ocupar su sitio en el coro $^{96}$. En los beneficios curados de Badajoz:

habiendo entrado en la dicha iglesia hizo oración al Santísimo Sacramento, abrió y cerró la puerta, tocó la campana, visitó, tocó y miró el Misal y dijo en él la oración de Espíritu Santo, abrió el arca del Santísimo y la volvió a cerrar ... ${ }^{97}$.

La estructura de este documento es la siguiente:

Invocatio.

Intitulatio.

Notificatio. No siempre.

90. Manuel María SÁNCHEZ UGARTE: Compendio elemental del Derecho Canónico precedido de una reseña histórica del mismo, tomo II, Madrid, Compañía Tipográfica, 1841. De cualquier forma, se produjo una diferenciación frente al feudalismo, puesto que el beneficio pasó a ser una institución autónoma, perteneciente a la Iglesia, que se transmitió de un beneficiado a otro, más allá de la relación personal existente entre los representantes de ésta y los beneficiarios (Émile LESNE: "Évêché et abbaye. Les origines du bénéfice ecclésiastique", Révue d'Historie de l'Église de France, 5-25 (1914), pp. 15-50).

91. Joaquín AGUIRRE: Curso de disciplina eclesiástica general y particular de España, tomo II, Madrid, Saavedra y Comp., 1849, p. 49.

92. Pierre REBUFFE: Praxis beneficiorum, p. 67.

93. Jean-Baptiste DANTOINE: Les règles du Droit Canon, Lyon, Claude Plaignard, 1720, p. 14.

94. Joaquín AGUIRRE: Curso de disciplina eclesiástica, pp. 96-7.

95. Pierre REBUFFE: Praxis beneficiorum, p. 70.

96. Sebastián BERARDI: Instituciones de Derecho Eclesiástico. Tomo II. Madrid 1791, p. 227.

97. Testimonio expedido por el notario Antonio Jiménez, de la posesión del beneficio curado concedido a Francisco Fraile (AEDMB. Fondos obispado, leg. 79, exp. $n^{\circ}$ 2093). 
Expositio. La directio solía estar implícita en ella.

Dispositio.

Sanctio: cláusula preceptiva, cláusula conminatoria.

Corroboratio.

Data.

Validatio. Firma del otorgante, refrendo del notario o secretario y sello. En cuanto a este último, como ocurrió en el caso de las licencias, en los instrumentos más antiguos, aparece en el vuelto del documento ${ }^{98}$.

\subsection{Título de oficial99}

La amplitud del dispositivo de algunos de estos documentos, particularmente el de aquellos donde se concedió la jurisdicción vicaria, esto es, los nombramientos de provisor o vicario, se debió a la necesidad de precisar con detalle su alcance. Dicha característica se afirmó en los otorgados en la segunda mitad del siglo XVI. Se puede comprobar, por otro lado, que los formularios empleados en Castilla se adoptaron también en las diócesis de la América hispánica ${ }^{100}$. La estructura fue:

Invocatio.

Intitulatio.

Expositio: donde se dejó constancia de la adecuación de la persona para el ejercicio del cargo, mediante fórmulas como: "confiando de la buena conciencia y diligencia de vos..."; "confiando de la rectitud y buena conciencia". La directio estaba implícita en la expositio.

Dispositio. Frecuentemente en dativo: "vos nombramos...", "vos criamos y hacemos...", "os criamos", o también: "le nombramos".

Se señalaba la obligación de prestar el juramento correspondiente ante notario. Esta alusión no fue fija.

Sanctio: cláusula de otorgamiento de poder, cláusula de salvaguarda y cláusula preceptiva. Ninguna de ellas era fija.

98. De acuerdo con la colación de una capellanía otorgada por el provisor Pero González el 10 de julio de 1529 (AEDMB. Fondos órdenes militares. Orden de Santiago, caja 2399, exp. s/n).

99. Apéndice documental: documento 2.

100. Véase, por ejemplo, el título de provisor concedido por fray Alonso de Montúfar, arzobispo de México, al licenciado don Esteban de Portillo el 31 de mayo de 1531 (Joaquín GARCÍA IZCALBALCETA: Descripción del arzobispado de México hecha en 1570 y otros documentos, México, José Joaquín Terrazas e hijas, 1897, pp. 314-317). 


\section{Corroboratio.}

Data.

Validatio. Suscripción del autor, refrendo del notario o secretario y sello.

\subsection{Dimisorias o testimoniales}

Se otorgaron a los clérigos que se desplazaron a otras diócesis. En ellas se dejó constancia de que no estaban excomulgados ni procesados. Por tanto, sirvieron de garantía para ejercer las labores propias de las órdenes que ostentaron aquellos y, en su caso, les permitieron promocionar a determinados oficios eclesiásticos.

No hemos encontrado ningún original de este documento en los obispados estudiados. Solamente hemos hallado una copia simple en romance.

Invocatio

Directio.

Salutatio.

Intitulatio

Salutatio

Expositio.

Dispositio.

Sanctio: cláusula exhortativa, cláusula obligativa o de reciprocidad.

Corroboratio.

Data.

Validatio: firma del autor, refrendo del notario y sello.

\subsection{Título de órdenes ${ }^{101}$}

La estructura de estos documentos no sufrió cambios sustanciales respecto a la de los instrumentos medievales que podemos encontrar en las diócesis de otros reinos. Los cambios se verificaron en el soporte. Esto influyó, a su vez, en el modo de aposición del sello. Si, en el caso del pergamino el sello, placado en papel, estuvo pendiente $^{102}$, los empleados en los documentos en papel fueron de placa y adhe-

101. Una transcripción de un título de órdenes en: Francisco Luis RICO CALLADO: “Una aproximación a los títulos de órdenes y las dimisorias en la Edad Moderna a través de la documentación de los obispados castellanos", Norba. Revista de Historia, 27-28 (2014-2015), pp. 281-297.

102. María Milagros CÁRCEL ORTí: "Notas de Diplomática episcopal...", p. 431. 
ridos en la parte inferior de los documentos. En lo que respecta al tenor, no hubo cambios en relación con los medievales, al menos hasta principios del siglo XVII:

Invocatio.

Notificatio.

Intitulatio.

Fecha en que se dieron las órdenes. Señalando el lugar concreto, esto es, la población y la iglesia o lugar sagrado.

Directio: se utilizaba el tratamiento "dilectum filium".

Expositio: se dejaba constancia de que el sujeto disponía de las condiciones necesarias como que era hijo legítimo, incluyendo, en caso de que no fuese residente en la diócesis, la licencia oportuna de su prelado: "de licentia sui prelati". En su caso, se indicaba la dispensa oportuna, particularmente de los intersticios, e, indefectiblemente la superación del examen oportuno: "examinatum et aprobatum ac in omnibus a Sacro Concilio tridentino requisitis idoneum...".

Dispositio.

Corroboratio: "in quorum fidem, praesentes litteras munus et sigillo nostris munitas ac per infrascriptum nostrum secretarium dari iussimus".

Data. Coincidente con la de la fecha de administración de las órdenes, de modo que se expresaba mediante formulismos como: "datae ut supra", "datis et actis ut supra".

Validatio: sello, suscripción del obispo y refrendo del secretario.

\subsection{La reverenda ${ }^{103}$}

Con este documento el prelado encargó la ordenación de uno de sus súbditos a otro obispo. Como se comprueba en el caso del priorato de León, esto se debió a que, durante una parte de la Edad Moderna, sus titulares carecieron de la potestad de orden. En cuanto a la calificación de estos instrumentos, pese a que en los trabajos contemporáneos se empleó el término de "dimisorias", en los obispados estudiados se calificaron como reverendas.

La estructura de este documento fue:

Intitulatio.

Directio: en el caso de los instrumentos otorgados por los priores santiaguistas u otros obispos, el destinatario fue el aspirante. En cambio,

103. Una transcripción de este tipo documental en: Francisco Luis RICO CALLADO: "Una aproximación a los títulos de órdenes y las dimisorias...", pp. 295-296. 
en los emanados por los priores alcantarinos, aquel fue una autoridad episcopal. En ambos casos estuvo precedida por una fórmula te cortesía: en el primero fue, usualmente: "dilecto nobis in Christo...". La empleada en el caso de los obispos aparece en el apéndice documental y tuvo un carácter más solemne: "Illustrissimis ac reverendissimis dominis archiepiscopis et episcopis"104.

Salutatio.

Dispositio. Aquí se observan numerosas variantes, dependiendo de la autoridad que emanó el documento. En el caso de los concedidos por las autoridades santiaguistas: "ut a quocumque malueris... promoveri... valeat, licentiam concedimus ipsique ut tibi... praedictum ordinem conferre possit..."105. En los más tardíos se observan ligeros cambios: "ut a quocumque malueris illustrissimo domino antistite gratiam et... primam clericalem tonsuram titulo sufficientiae promoveri possit et valeas licentiam concedimus... tibi conferendi tenore praesentium facultatem impartimur et rogamus"106. En los otorgados por los obispos de Cáceres: "ut a quocumque... tibi elargimus licentiam... Ut tibi praemissum conferat ordinem facultatem impartimur"107.

Corroboratio.

Data.

Validatio. Como en el caso de los títulos de órdenes.

\subsection{Mandamiento ${ }^{108}$}

Invocatio.

Intitulatio.

Directio.

Salutatio: no es fija.

Notificatio: "hacemos saber". No permanente. Como en el caso de la salutatio, aparece en los casos en que se transmitieron órdenes del superior $^{109}$.

Expositio. Si se trataba de cumplir una orden del consejo de órdenes o de otro superior, se trasladaban los documentos recibidos. De esto tenemos

104. AEMB. Fondos obispado, caja de órdenes, 1798, exp. s/n.

105. Ibidem, caja órdenes, 1600-1699 (I), exp. s/n.

106. AEDMB. Fondos obispado, caja de órdenes, 1795, exp. s/n.

107. Ibidem, caja de órdenes, 1798, exp. s/n.

108. Apéndice documental: documento 3.

109. AEDMB. Fondos órdenes militares. Orden de Santiago, leg. 495, exp. no 19136. 
múltiples muestras en el caso de la documentación de los provisores santiaguistas, si bien se detectan irregularidades, particularmente en la documentación del siglo XVII ${ }^{110}$.

Dispositio: "mandamos", "mando".

Sanctio: cláusula penal, cláusula de cumplimiento. A ellas se podían añadir otras, como la prohibitiva, si bien no era fija. Asimismo, se podía incluir una orden referida a la certificación de la recepción del documento y su reenvío a otros destinatarios: "y de haber recibido este nuestro despacho y de quedar entendidos de su contenido pondrán certificación a el pie y con el portador que va a esta diligencia despacharán con la mayor brevedad sin detenerle..."111.

Data.

Validatio: suscripción del autor y refrendo del notario o secretario. En raras ocasiones se incluyó el sello ${ }^{112}$.

\section{Conclusiones}

En el estado actual de conocimiento de las cuestiones planteadas en este trabajo, podemos subrayar la existencia de rasgos comunes en la documentación emanada en diferentes diócesis. Esto atañe no solamente a las tipologías, tanto en lo que incumbe a sus caracteres internos como externos, sino también a su conscriptio.

Desde la Edad Media se produjo una división del gobierno en las diócesis, de modo que los obispos confiaron el ejercicio de una parte importante de su potestad, particularmente en lo que respecta a las atribuciones "jurisdiccionales", a sus provisores y vicarios generales. Estos expidieron documentos intitulados por ellos mismos, cuyo tenor coincidió con los del obispo. En este sentido, como hemos visto, se impuso el tenor basado en la littera, asumido en la Edad Media en diferentes diócesis españolas, si bien las mejor estudiadas son las situadas en la Corona de Aragón.

Junto a ello, debemos destacar el decreto que no solamente estuvo ligado con los trámites gubernativos, sino que sirvió, a su vez, para comunicar las resoluciones a las partes. Este uso coincidió con las prácticas que se impusieron en los órganos de la administración real, por citar el caso mejor conocido, posibilitando el empleo de documentos más simples, polivalentes, dotados, a su vez, de fehaciencia.

110. Ibidem, leg. 918, exp. $\mathrm{n}^{\circ} 31088$.

111. Ibidem, leg. 1528, exp. $\mathrm{n}^{\circ} 33558$.

112. Idem. 
Uno de los principales problemas con los que se topa el estudioso de la documentación episcopal en la Edad Moderna es la conservación de los fondos. Esta situación cambió en el siglo XIX, particularmente en lo que respecta a los trámites seguidos en la secretaría del obispo. El aparente conservadurismo de los usos documentales eclesiásticos permite plantear la hipótesis de que los expedientes más tardíos pueden contribuir a aclarar algunas de las cuestiones estudiadas en este trabajo.

\section{Bibliografía}

AGUIRRE, Joaquín: Curso de disciplina eclesiástica general y particular de España, tomo II, Madrid, Saavedra y Comp., 1849.

ANTONIO GOMES, Saul: "As 'matrículas de ordens': de elemento diplomático a acontecimento histórico. Subsídio para o estudo do clero português no final dos tempos medievos", Lusitania Sacra, 13-14 (2001-2002), pp. 229-266.

BERARDI, Sebastián: Instituciones de Derecho Eclesiástico. Tomo II, Madrid 1791.

CABANES CATALÁ, María Luisa y BALDAQuÍ ESCANDELL, Vicente Ramón: "Sigilografía episcopal orcelitana de los siglos XVI y XVII en el Archivo Municipal de Elche", Actas del primer Coloquio de Sigilografía. Madrid 2 al 4 de abril de 1987, Madrid, 1990, pp. 309-316.

CÁRCEL ORTÍ, María Milagros: "El documento episcopal. Estado actual de sus estudios", Boletín de la Sociedad Castellonense de Cultura, LVIII (1982), pp. 471-511.

CÁRCEL ORTÍ, María Milagros: "Notas de Diplomática episcopal: títulos de órdenes sagradas", Hispania Sacra, 45 (1993), pp. 429-458.

CÁRCEL ORTÍ, María Milagros: "Diplomática episcopal de Valencia (12401300)", en Christoph HAIDACHER, y Charles KÖFLER (eds.): Die Diplomatik der Bischofsurkunde vor 1250. La Diplomatique épiscopale avant 1250, Innsbruck, Tiroler Landesarchiv, 1995, pp. 393-401.

CÁRCEL ORTÍ, María Milagros: "Casa, corte y cancillería del obispo de Valencia Hug de Llupià (1398-1427)", Anuario de estudios medievales, 28 (1998), pp. 635-660.

CÁRCEL ORTÍ, María Milagros: "Las tasas de la cancillería valentina y el 'grati' en los registros del obispo Hugo de Llupià (1408-1425)", Analecta Sacra Tarraconensia, 72 (1999), pp. 55-108.

CÁRCEL ORTÍ, María Milagros: "Ad servicium Ecclesiae dedicandi. Clérigos aragoneses ordenados en Valencia en el siglo XV", Aragón en la Edad Media, 16 (2000), pp. 163-164. 
CÁRCEL ORTÍ, María Milagros: "Un registro de colaciones de Hug de Fenollet y Vidal de Blanes, obispos de Valencia (1350-1359)", Estudis castellonencs, 9-2 (2000-2002), pp. 599-772.

CÁRCEL ORTÍ, María Milagros: “Documentación judicial de la administración episcopal valentina: procesos del Oficialato de Valencia y Xátiva (siglos XIV-XVI)", en Giovanna NICOLAJ: La diplomática dei documenti giudiziari (dai placiti agli acta-secc. XII-XV): Bologna 12-15 settembre 2001, Città del Vaticano, Scuola Vaticana di Paleografia, Diplomatica e Archivistica, 2004, pp. 137-205.

CÁRCEL ORTÍ, María Milagros: Un formulari i un registre del bisbe de València en Jaume d'Aragó (Segle XV), Valencia, Universidad de Valencia, 2005.

CÁRCEL ORTí, María Milagros: "Notas de diplomática episcopal: reparación de dos letras de tonsura", Saitabi: revista de la Facultad de Geografía i Història, 59 (2009), pp. 211-230.

CÁRCEL ORTÍ, María Milagros: "Los registros episcopales", en Elena CANTARELL BARELLA y Mireia COMAS (coords.): La escritura de la memoria: los registros, Barcelona, Promociones y Publicaciones Universitarias, PPU, 2011, pp. 133-148.

CÁRCEL ORTÍ, María Milagros: "Un registro de colaciones del obispo de Valencia Jaume d'Aragó de 1383", Analecta sacra tarraconensia: revista de ciencias histórico-eclesiásticas, 89 (2016), pp. 1213-246.

CÁRCEL ORTÍ, María Milagros y PONS ALÓS, Vicente: "Curia, casa y corte valentina del cardenal Rodrigo de Borja, obispo de Valencia (1458-1492)", en María del Val GONZÁLEZ DE LA PEÑA: Estudios en memoria del profesor Dr. Carlos Sáez: homenaje, Alcalá de Henares, Universidad de Alcalá de Henares, 2007, pp. 415-438.

Constituciones sinodales del obispado de Palencia ordenadas por mandado del ilustre y reverendísimo señor don Luis Cabeza de Vaca, obispo del dicho obispado, Conde Pernía, s. I., s. d.

Constituciones synodales fechas y promulgadas en la primera sínodo que se celebró en la ciudad y obispado de Valladolid por el ilustrísimo y reverendísimo señor don Juan Baptista de Azevedo, patriarca de las Indias, segundo obispo del dicho obispado e inquisidor apostólico general en los reynos y señoríos de su Magestad. Valladolid 1607.

CRUZ HERRANZ, Luis Miguel de la: "Documentación eclesiástica no pontificia", en Juan Carlos GALENDE DÍAZ (dir.): La diplomática y sus fuentes documentales, Madrid, Asociación de Amigos del Archivo Histórico-Nacional y Universidad Complutense, 2020, pp. 127-186.

DANTOINE, Jean-Baptiste: Les règles du Droit Canon, Lyon 1720, p. 14.

GARCÍA IZCALBALCETA, Joaquín: Descripción del arzobispado de México hecha en 1570 y otros documentos, México, José Joaquín Terrazas e hijas, 1897. 
GÓMEZ GÓMEZ, Margarita: Forma y Expedición del Documento en la Secretaría de Estado y del Despacho Universal de Indias, Sevilla, Universidad de Sevilla, 1993.

HERREROS MOYA, Gonzalo J.: Heráldica, sociedad y patrimonio. Los obispos de Córdoba, su origen social y escudos de armas (siglos XIII-XXI), tesis de doctorado, Córdoba, Universidad de Córdoba, 2020.

LESNE, Émile: "Évêché et abbaye. Les origines du bénéfice ecclésiastique", Révue d'Historie de l'Église de France, 5-25 (1914), pp. 15-50.

LORENZO CADARSO, Pedro Luis: "La correspondencia administrativa en el Estado absoluto castellano (siglos XVI-XVII)", Tiempos Modernos, 2- 6 (2001).

LORENZO CADARSO, Pedro Luis: La documentación judicial en la época de los Austrias. Estudio archivístico y diplomático, Cáceres, Universidad de Extremadura, 2004.

MAILLANE, Durand de: Dictionnaire de Droit Canonique et de pratique bénéficiale conferé avec les maximes et la jurisprudence de France c'est-àdire, avec les usages et libertés de l'Église gallicane, les pragmatiques et concordats, les ordonnances, édits et déclarations de nos Rois, les arrêts des Parlements et $d u$ Grand-Conseil, les saines opiniones des auteurs français et la pratique des officialités, tomo II, París, Jean Baptiste Bauche, 1759.

MARÍN LÓPEZ, Rafael: "Diplomática eclesiástica granadina. Estructura burocrática, gestión y tipos documentales en el siglo XVI", Archivo teológico granadino, 60 (1997), pp. 121-199.

MARSILLA DE PASCUAL, Francisco Reyes: "En torno a la diplomática episcopal y capitular castellana bajomedieval: una aproximación", Miscelánea medieval murciana, 19-20 (1996), pp. 153-172.

OSTOS SALCEDO, Pilar: "Documentos y cancillería episcopal de Burgos, anterior a 1300", en Christoph HAIDACHER, y Charles KÖFLER (eds.): Die Diplomatik der Bischofsurkunde vor 1250. La Diplomatique épiscopale avant 1250, Innsbruck, Tiroler Landesarchiv, 1995, pp. 429-451.

PARDO RODRÍGUEZ, María Luisa: “Documentos y cancillerías episcopales de la Andalucía bética en el siglo XIII. Las sedes de Baeza-Jaén, Córdoba y Sevilla", en Christoph HAIDACHER, y Charles KÖFLER (eds.): Die Diplomatik der Bischofsurkunde vor 1250. La Diplomatique épiscopale avant 1250, Innsbruck, Tiroler Landesarchiv, 1995, pp. 453-466.

REBUFFE, Pierre: Praxis beneficiorum, Lugduni, Guglielmi Rovillii, 1620.

PINEDA ALFONSO, José Antonio: El gobierno arzobispal de Sevilla en la Edad Moderna (siglos XVI-XVII), Tesis doctoral, Sevilla, Universidad de Sevilla, 2015.

PUEYO COLOMINA, Pilar: "Aproximación a una tipología documental de los registros de actos comunes de la diócesis de Zaragoza durante el arzobispa- 
do de Pedro de La Jugie (1345-1347)”, Aragón en la Edad Media, 8 (1989), pp. 523-536.

PUEYO COLOMINA, Pilar: "Diplomática episcopal Cesaraugustuana anterior a 1318", en Christoph HAIDACHER, y Charles KÖFLER (eds.): Die Diplomatik der Bischofsurkunde vor 1250. La Diplomatique épiscopale avant 1250, Innsbruck, Tiroler Landesarchiv, 1995, pp. 411-427.

PUEYO COLOMINA, Pilar: "El registro de actos comunes del arzobispo de Zaragoza, Pedro de La Jugie (1346-1347)", Aragón en la Edad Media, 10-11 (1993), pp. 269-312.

PUEYO COLOMINA, Pilar: "Licencias para pedir limosnas, con o sin indulgencias, otorgadas por los arzobispos de la diócesis de Zaragoza en la segunda mitad del siglo XIV", Aragón en la Edad Media, 16 (2000), pp. 683-708.

RÁBADE OBRADÓ, María Pilar: "Una aproximación a la cancillería episcopal de Fray Lope de Barrientos, obispo de Cuenca", Espacio, Tiempo y Forma, 7 (1994), pp. 191-204.

RICO CALLADO, Francisco Luis: “Una aproximación a los títulos de órdenes y las dimisorias en la Edad Moderna a través de la documentación de los obispados castellanos", Norba. Revista de Historia, 27-28 (2014-2015), pp. 281-297.

RICO CALLADO, Francisco Luis: "La documentación gubernativa diocesana en la Edad Moderna a través de los expedientes de concursos de beneficios curados", Ibersid: revista de sistemas de información y documentación, 11-1 (2017), pp. 51-62.

RICO CALLADO, Francisco Luis: "El gobierno de las diócesis y su configuración institucional: las curias diocesanas y su estructura en la Corona de Castilla en la Edad Moderna (SS. XVI-XVIII)", Ius Canonicum, 60-120 (2020), pp. $1-45$.

RICO CALLADO, Francisco Luis: "La correspondencia gubernativa en los obispados españoles en la Edad Moderna (siglos XVII-XVIII)", Documenta \& instrumenta, 19 (2021), en prensa.

RIESCO TERRERO, Ángel: "Consideraciones en torno a la Diplomática episcopal antigua y medieval (s. V-XIII)", en Homenaje al profesor Juan Torres Fontes, vol. II, Murcia, Universidad de Murcia, 1987, págs. 1387-1399.

RUBIO MERINO, Pedro: Archivística eclesiástica: nociones básicas, Sevilla, Guadalquivir Ediciones, 1999.

SÁNCHEZ UGARTE, Manuel María: Compendio elemental del Derecho Canónico precedido de una reseña histórica del mismo, tomo II, Madrid, Compañía Tipográfica, 1841.

SANZ FUENTES, María Josefa: "Documento y cancillería episcopal en Oviedo anterior a 1300", en Christoph HAIDACHER, y Charles KÖFLER (eds.): Die 
Diplomatik der Bischofsurkunde vor 1250. La Diplomatique épiscopale avant 1250, Innsbruck, Tiroler Landesarchiv, 1995, pp. 467-482.

SANZ SANCHO, Iluminado: "Notas sobre la casa de los obispos de Córdoba en la Edad Media", Espacio, Tiempo y Forma, 18 (2005), pp. 245-264.

TELLECHEA IDÍGORAS, José Ignacio: “El cabildo catedral salmantino ante el estatuto de limpieza de sangre: historia de una doble tentativa fallida (15481559)", Salmaticensis, 33-3 (1986), pp. 345-369.

VÁZQUEZ BERTOMEU, Mercedes: "La audiencia arzobispal compostelana", Cuadernos de estudios gallegos, 110 (1998), pp. 9-29.

VEGA, Alonso de: Espejo de curas, utilísimo para todo género de eclesiásticos, y principalmente para aquellos que tienen cargo de ánimas, por comprenderse en él todo lo que les es necesario para cumplir con la obligación que tienen, Madrid, Francisco de Robles, 1602. 


\section{Apéndice documental ${ }^{113}$}

\section{Documento 1}

AEDMB, Fondos obispado, legajo 50, exp. s/n

Tipo documental: licencia.

Asunto: el obispo Amador Merino Malaguilla concede licencia para confesar a Francisco Zamorano, presbítero de Jerez de los Caballeros.

Data: Burguillos, 3 de marzo de 1752.

\section{[Cruz]}

Nos, don Amador Merino Malaguilla, por la gracia de Dios y de la santa sede apostólica, obispo de Badajoz, del consejo de su Majestad, etc.

Confiando de la virtud, ejemplar vida y suficiencia de don Francisco Zamorano, presbítero de Jerez de los Caballeros, de este nuestro obispado, por la presente le damos licencia para que por el tiempo de un año y sin perjuicio del derecho parroquial, pueda en nuestro obispado administrar el santo sacramento de la penitencia a los hombres que con él se quisieren confesar, absolviéndoles de todos sus pecados, excepto de los reservados a su Santidad y a nos, por derecho y constituciones sinodales y teniendo cuarenta años de edad, o haciendo oficio de cura, y no en otra forma, pueda, asimismo, confesar mujeres, excepto a las religiosas de nuestra jurisdicción. Y no confiese a las exentas de ella, aunque tenga licencia de sus superiores regulares, sin que primero exhiba ante nos y obtenga nuestra especial aprobación para ello, según lo mandado en la constitución de la Santidad de Inocencio XIII de feliz memoria, que empieza: "Apostolici ministerii", su data en Roma, en 18 de mayo de 1723, confirmada y mandada guardar por la santidad de Benedicto XIII en repetidos breves y constituciones cuyas disposiciones y las apostólicas que prohíben el uso de la facultad de absolver fuera del tiempo personas y territorio a que se extiende esta nuestra licencia y los decretos del Santo Tribunal de la Inquisición que prescriben el lugar y circunstancias con que se debe administrar a las mujeres Santo Sacramento de la penitencia. Observará en todo y por todo, sin contravenir a cosa alguna, so color de cualquiera exención, costumbres o privilegios y sus participaciones por quinto todos están revocados y declarado nuevamente por la santidad de Benedicto XIII en su breve que empieza: "Etsi graviter affecti alguna sumus", su data en Roma en 21 de septiembre de 1729, no hallarse derogado en manera alguna el citado "Apostolici ministerio", ni sus confirmatorios; antes bien, encarga de nuevo su

113. Utilizamos, básicamente, los criterios propuestos en Pedro Luis LORENZO CADARSO: La documentación judicial en la época de los Austrias. Estudio archivístico y diplomático, Universidad de Extremadura, Cáceres, 2004, pp. 129-132, con la salvedad de que no señalamos los saltos de línea. 
práctica y puntual observancia. Y le exhortamos y encargamos, in visceribus Jesuchristi que, antes de dar la absolución a los penitentes, reconozca en los que prudentemente debe dudar si saben la doctrina cristiana, entendiendo a lo menos lo que precisamente han de creer y obrar y recibir para salvarse. $\mathrm{E}$ instruirá en ello a los que lo ignoraren y, siendo necesario, le suspenderá la absolución, procediendo con prudente reflexión, sobre todo. Dada en BurguiIlos, a tres días del mes de marzo de mil setecientos y cincuenta y dos.

Amador, obispo de Badajoz [rúbrica]

Por mandado del obispo mi señor,

Cristóbal Manuel de Arce [rúbrica]

\section{CASOS RESERVADOS AL PRELADO}

1. Acceso carnal con mora o judía. 7. Sacrilegio de manos violentas o de inmunidad de la iglesia

2. Homicidio voluntario.

3. Tomar el cuerpo de nuestro señor 8. Excomunión puesta por nos o por Jesucristo, óleos, aras u otra cualquier nuestro provisor o jueces eclesiásticosa sagrada para hacer maleficios cos, excepto si se ponen por deudas o cosas hurtadas que, satisfechas las partes, pueden absolver el cura o tenientes

5. Cercos y embustes para hablar con 9. Incesto dentro de segundo grado los demonios

10. Sodomía y bestialidad

6. Órdenes per saltum o sin reveren- 11. Incendio hecho de propósito en das del prelado graves y dudosos 


\section{Documento 2}

Archivo Catedralicio de Badajoz (ACB), leg. 9, documento s/n

Tipo documental: título o nombramiento de oficial.

Asunto: el obispo Juan Marín de Rodezno nombra al licenciado Blas Gómez de Luna vicario eclesiástico de la villa de Fregenal.

Data: Badajoz, 27 de noviembre de 1796.

\section{[Cruz]}

Don Juan Marín de Rodezno, por la gracia de Dios y de la santa sede apostólica obispo de Badajoz, vicario general del ejército de Extremadura del consejo de su Majestad. Por cuanto la vicaría de la villa de Fregenal y su partido de este nuestro obispado está al presente vacante por fin y muerte de don Joseph de Amaya presbítero, vicario eclesiástico que fue de la dicha villa y su vicaria, confiando la prudencia y virtud y suficiencia del licenciado Blas Gómez Luna, cura propio de la iglesia parroquial de la villa de Fregenal, que bien y fielmente hará lo que por nos y nuestro provisor le fuere mandado y lo que convenga para la buena administración de justicia le creamos, deputamos y nombramos por nuestro vicario eclesiástico de la dicha villa de Fregenal, su jurisdicción y vicaria y le damos poder y facultad cual de derecho se requiere y es necesario para que por el tiempo que fuere de nuestra voluntad pueda, como tal vicario, oír conocer, juzgar y sentenciar interlocutoria y definitivamente todas las causas civiles que ante él concurrieren de la dicha vicaría, excepto las decimales, cuando se trate del derecho decimal y las beneficiales, matrimoniales y criminales. Las cuales y cada una de ellas reservamos a nos y a nuestro provisor $y$ vicario general y, en la dicha forma, pueda dar y dé cualesquiera mandamientos censuras y demás despachos que convengan a la buena administración de justicia y las sentencias definitivas, no interpuesta apelación que diere las pueda llevar y lleve a debida ejecución y, de las que se apelaren, otorgar para ante dicho nuestro provisor y vicario general, como a tribunal superior y principal; $y$, en las causas criminales que, por denunciación de oficio o querella de parte, se ofrecieren de cualesquiera delito y pecados públicos, pueda hace información e informaciones sumarias y remitirlas luego al dicho nuestro tribunal y en los casos que piden captura y hubiere sospecha de fuga de los reos y delincuentes, los pueda prender y encarcelar y enviarlos a buen recaudo; junto con los procesos e informaciones, autos y diligencias que hiciere al dicho mi tribunal, para que en él se provea y haga justicia, sin conocer ni entrometerse el dicho vicario en otra causa ni caso alguno, más que en lo que dicho es; sin exceder de lo permitido declarado y dispuesto por las constituciones sinodales de este dicho nuestro obispado. Y, por razón de dicho oficio, pueda llevar y lleve los derechos y emolumentos que le tocan y pertenecieren según el arancel real y el que está en dichas sinodales y, asimismo, le damos facultad para que en sus ausencias y enfermedades pueda nombrar y nombre u teniente persona hábil y suficiente que ejerza dicho oficio; que para todo lo que dicho es y lo a ello ane- 
xo y concerniente le cometemos nuestras veces, con facultad de excomulgar y absolver y de implorar el auxilio de brazo seglar, con tal que antes que comience a ejercer dicho oficio haga juramento de usarlo bien fielmente en manos y ante el padre rector del colegio de la compañía de Jesús de la dicha villa de Fregenal a quien lo cometemos y que se lo reciba pro ante cualquier escribano o notario. Y mandamos a todas las personas eclesiásticas y seculares de dicha villa de Fregenal y su vicaría admitan y hayan y tengan por tal nuestro vicario eclesiástico de ella, al dicho licenciado Blas Gómez Luna, y le guarden y hagan guardar las honras preeminencias y prerrogativas que le fueren debidas por razón de su oficio como y de la manera que se han guardado y debido guardar a los demás vicarios sus antecesores. En testimonio de lo cual le mandamos dar y dimos el presente, firmado de nuestra mano, sellado con el sello de nuestras armas y refrendado del infrascripto nuestro secretario de cámara. En Badajoz y nuestros palacios episcopales, veinte y siete días del mes de noviembre de mil y seiscientos y noventa y seis años.

[sello]

El obispo de Badajoz [rúbrica]

Por mandado del obispo mi señor, Miguel de Bascarán [rúbrica] 


\section{Documento 3}

AEDMB. Fondos obispado, leg. 9, exp. $\mathrm{n}^{\circ} 187$.

Tipo documental: mandamiento.

Asunto: el obispo Manuel Pérez Minayo ordena que los beneficiados y titulares de beneficios simples y capellanías que no están ordenados presenten una copia certificada de sus partidas de nacimiento, con el fin de averiguar si tienen veintiún años.

Data: Albuquerque, 2 de agosto de 1769.

\section{[Cruz]}

Nos, don Manuel Pérez Minayo, por la gracia de Dios y de la santa sede apostólica, obispo de Badajoz, del consejo de su Majestad, etc.

Por cuanto nos consta, por ciertos informes que hemos tomado, que los cogedores depositarios tesoreros fieles terceros repartidores y administradores de diezmos y primicias de este nuestro obispado y de otros bienes efectos y rentas que pertenecen a beneficios simples préstamos y capellanías, con servicio en diferentes iglesias parroquiales y capillas de él, acuden y están acudiendo con aquellas partes de dichos diezmos primicias y demás rentas a los tales beneficios simples préstamos y capellanías tocantes y pertenecientes a distintas personas por la cualidad de beneficiados y capellanes propios, sin que al tiempo de hacer los pagos o recudimientos de dichos diezmos primicias y rentas precedan los requisitos precisos de presentarse fe de vida de los dichos beneficiados y capellanes, autorizada en pública forma y el de hacer constar que, teniendo veintiún años cumplidos, se hallan legítimamente ordenados in sacris o que no llegan a la referida edad, siendo cierto que, así en esta villa, como en otros pueblos de este dicho nuestro obispado se sirvan beneficios simples préstamos y capellanías que los gozan y poseen personas no conocidas y que no tienen acreditados dichos requisitos, como debían haberlo ejecutado, a causa de ser forasteros y extraños de este dicho nuestro obispado los tales poseedores de dichos beneficios y capellanías. Por tanto, y para evitar los graves perjuicios que pueden resultar de continuarse haciendo dichos pagos sin la cierta ciencia de que se hacen a legítimos y verdaderos beneficiados y capellanes y sin que acrediten o que no tienen los veintiún años de edad o que, teniéndola, se hallan legítimamente ordenados in sacris, mandamos, en virtud de santa obediencia y bajo de la pena de treinta ducados de vellón, aplicados a obras país a nuestro arbitrio a todas y cada uno de dichos cogedores depositarios, tesoreros, terceros repartidores y administradores de diezmos y primicias de esta villa y demás pueblos de este nuestro obispado y a cualesquiera otra persona, a cuyo cargo se halle el pago de dichos diezmos y primicias y otro cualesquiera género de efecto y rentas frutos y pertenecientes a dichos beneficios simples y capellanías, que han residido y residen fuera de este dicho nuestro obispado con los efectos diezmos y primicias rentas de dichos beneficios préstamos y capellanías y que, por 
el contrario, retengan los dichos cogedores, depositarios, renteros repartidores y administradores por vía de depósito y embargo los dichos diezmos primicias y demás efectos, hasta tanto que por todos y cada uno de dichos beneficiados y capellanes ausentes se les presente la correspondiente fe de vida autorizada en pública forma, con testimonio auténtico de la partida de bautismo, a fin de averiguar, en caso que no hagan constar hallarse ordenado in sacris, si tienen o no los veintiún años, con prevención de que, entregados que le sean los documentos que verifiquen el orden sacro o no tener la edad competente para recibirlo, los remitan dichos cogedores, tesoreros, terceros repartidores y administradores, antes de hacer pago alguno a nuestras manos, por la del infrascripto nuestro secretario de cámara para su inspección y reconocimiento y examinada es legítima, se les volverán para que hagan dichos pagos que en dichos términos y no en otro. Lo harán y continuaran haciendo con condición de que, por lo que toca a la fe de vida, se les ha de presentar anualmente o en los tiempos tercios o plazos en que digan de hacer dichos pagos lo que así cumplirán dichos cogedores depositarios tesoreros terceros repartidores y administradores de dichos efectos de sus primicias y rentas, con apercibimiento de que, constando de las respectivas notificaciones que a cada uno de ellos se les harán y no de su cumplimiento, precederemos en su contra a la ejecución de dicha multa y a que paguen segunda vez de sus propios bienes la cantidad o cantidades de maravedíes, granos, demás efectos que en otra manera pagasen y, bajo la pena de diez ducados de multa que, asimismo, aplicamos a obras país a nuestro arbitrio. Mandando a cualesquiera notario eclesiástico que con este sea requerido lo notifique y haga saber en los pueblos, a donde se dirigiese, a sus respectivos cogedores, tesoreros, depositarios, terceros repartidores y administradores, poniendo por fe y diligencia las que se hiciesen. Dado en la villa de Alburquerque y nuestra santa visita, a dos días del mes de agosto de mil setecientos setenta y nueve años.

Manuel, obispo de Badajoz [rúbrica] Por mandado de su señoría ilustrísima, el obispo mi señor, Don José Ares, secretario [rúbrica] 